\title{
胺及其衍生物的非酰基化动力学拆分
}

\author{
唐亮李雪薇 谢芳* 张万斌 \\ (上海交通大学化学化工学院 上海市手性药物分子工程重点实验室 上海 200240)
}

\begin{abstract}
摘要 光学纯胺在合成与药物化学领域都有着广泛的应用, 发展其高效的合成方法一直以来是有机化学界的研究热 点. 其中通过 $\mathrm{N}$ 酰基化及去酰基化动力学拆分方法获得光学纯胺化合物, 已经成为合成手性胺类化合物的重要方法. 近年来, 基于非酰基化(或去酰基化)的不对称反应实现外消旋胺的动力学拆分的报道不断涌现，包括一些氨基不参与 反应的非酰基化(或去酰基化)不对称反应的外消旋胺的动力学拆分. 根据氮原子是否参与反应以及反应类型的不同, 总结了外消旋胺的化学催化动力学拆分的研究进展.
\end{abstract}

关键词 光学纯胺; 动力学拆分; 非酶催化; 非酰基化(去酰基化); 不对称催化反应

\section{Catalytic Kinetic Resolution of Amines and Their Derivatives by Non-acylation Reaction}

\author{
Tang, Liang Li, Xuewei Xie, Fang* Zhang, Wanbin \\ (Shanghai Key Laboratory for Molecular Engineering of Chiral Drugs, School of Chemistry and Chemical Engineering, \\ Shanghai Jiao Tong University, Shanghai 200240)
}

\begin{abstract}
Enantiopure amines are important building blocks with a plethora of applications in the fields of medicine, agriculture and materials. Kinetic resolution (KR) of racemic amines is one of the most important methods for obtaining enantiopure amines. However, KR of amines is little investigated because of their high reactivity and coordinating ability in the corresponding KR of alcohols. Till now, major developments using non-enzymatic catalysts for KR of amines have been extensively achieved by catalytic acylation (or deacylation). Only recently the non-acylation KR of amines is improving. The relatively wide range of different catalytic asymmetric reactions have been employed as strategies for the efficient KR of amines. For some cases, the asymmetric reactions do not involve with nitrogen atoms of racemic substrates. This review aims to introduce the development of the non-acylation KR of amines for the synthesis of enantiopure amines.

Keywords enantiopure amines; kinetic resolution; nonenzymatic; non-acylation; catalytic asymmetric reactions
\end{abstract}

手性胺类化合物广泛存在于自然界，是蛋白质、核 酸、激素、抗生素和生物碱等生理活性物质的重要组成 部分. 同时, 因为高密度的结构信息和生成氢键的能力, 手性胺也是重要的药物, 如用于镇痛、镇咳、催眠的 Codeine ${ }^{[1]}$, 治疗抑郁症的 Sertraline $e^{[2]}$, 减肥药物 Sibutramine ${ }^{[3]}$ 以及 HIV 蛋白酶抑制剂 Lopinavir ${ }^{[4]}$ 等. 另 外, 手性胺作为重要的中间体和砌块, 被广泛应用于有 机合成中. 在有机不对称催化中, 手性胺作为金属配体 或小分子催化剂也起着重要的作用 ${ }^{[5]}$. 因为手性胺的广 泛应用价值, 它的合成一直吸引着化学家们的巨大兴 趣. 目前, 合成手性胺的方法已经有许多报道, 而动力
学拆分(Kinetic Resolution, 简称 $\mathrm{KR})^{[6]}$ 则是其中一类重 要方法.

在手性化合物的众多不对称合成方法中, KR 是最 古老的一种. KR 在现有方法中是独一无二的, 因为很多 情况下它可以制备 $e e$ 值非常高的对映异构体, 远远超 出现代分析技术的检测极限. 这一特点引起了学术界和 产业界的广泛兴趣, 并被认为是自然界中手性起源之谜 的可能解释之一. 另一个重要特点是 KR 几乎可以与所 有的对映选择性合成方法结合使用, 并且几乎可以用于 合成所有的手性底物. 因此, KR 已被广泛应用于外消旋 化合物的手性分离, 其中最负盛名的一种应用是通过生

\footnotetext{
* Corresponding author. E-mail: xiefang@sjtu.edu.cn

Received October 10, 2019; revised November 11, 2019; published online November 21, 2019.

Project supported by the National Natural Science Foundation of China (No. 21572129).

国家自然科学基金(No. 21572129)资助项目.
} 
物酶或小分子催化的酰基化反应来分离拆分手性产物 与手性原料.

值得注意的是, 无论生物酶法还是化学法都能实现 一级或二级醇通过酰基化的高效拆分 ${ }^{[7]}$, 并且已在工业 界实现了大规模应用. 相对于醇类化合物, 胺类化合物 (一级或二级胺)通常具有较强的亲核性, 因此用任何常 规酰基化试剂进行酰基化反应时, 都会导致快速的酰基 化反应, 从而降低反应的的选择性; 同时, 胺类化合物 也容易与金属催化剂配位，从而降低反应活性和选择 性. 因此, 胺类化合物的动力学拆分更具有挑战性, 发 展也较为缓慢. 2001 年, 自 Fu 课题组 ${ }^{[8 a]}$ 报道了首例有机 小分子催化不对称酰基化动力学拆分的研究工作以来 (Scheme 1), Seidel 等 ${ }^{[8 b-8 d]}$ 课题组也相继报道了基于不对 称酰基化的拆分成果. 这些不对称酰基化的拆分都局限 于一级胺、二级环状胺以及氮上具有较低亲核性的酰胺 [9]等底物。<smiles>[14CH3]C(N)Br</smiles>

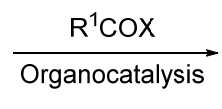

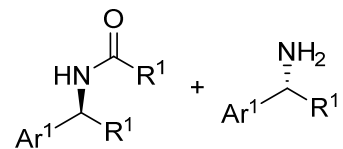

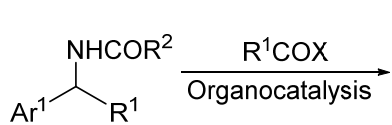<smiles>[R]C([Y19])NC([R])[R]</smiles>

图式 1 有机小分子催化不对称酰基化动力学拆分 Scheme 1 Organocatalyzed acylation KR of amines

近年来随着不对称催化反应的不断发展, 采用非酰 基化的不对称催化反应来实现胺类化合物的动力学拆 分越来越受到化学家们的关注, 并且获得了越来越多的 研究成果. 根据氮原子是否参与反应，对该类非酰基化 化学动力学拆分进行了梳理分类, 并根据反应类型的不 同对动力学拆分研究现状进行了综述.

\section{1 氮参与反应的非酰基化化学动力学拆分}

近年来, 采用非酰基化的化学动力学拆分制备光学 纯手性胺的方法得到化学家们越来越多的关注与研究. 其中，氮原子参与催化反应的例子已经得到了许多报 道. 根据氮原子参与反应的类型可将其分为非酶催化的 氧化还原动力学拆分、氮杂环丙烷不对称开环动力学拆 分及 $2 H$-氮杂丙烯啶的不对称加成动力学拆分、 $\mathrm{C}-\mathrm{X}$ 活化动力学拆分、取代动力学拆分及其他类型反应的动 力学拆分等.

\section{1 非酶催化的氧化还原动力学拆分}

通过二级醇类化合物不对称脱氢生成潜手性酮，从 而合成手性二级醇的方法被称为氧化动力学拆分 (OKR)，目前许多使用过渡金属催化的醇类化合物的
OKR 法已经被开发出来 ${ }^{[10]}$. 相比之下，胺类化合物的 OKR 法存在许多挑战，主要是因为氮原子容易被氧化, 胺类化合物作为路易斯碱通常会和金属配位，从而使催 化剂失活. 因此, 胺类化合物的 OKR 研究最先从叔胺 类底物开始. 早在 20 世纪八、九十年代, Sharpless 课题 组 ${ }^{[1]}$ 就通过 $\mathrm{Ti}$ 催化的选择性 $\mathrm{N}$ 氧化实现了叔胺类化合 物的 OKR. 得到了手性 $\beta$-氨基醇类化合物. 而在 2016 年, Yamamoto 课题组 ${ }^{[12]}$ 发展了 $\mathrm{Ti}$ 催化的 $\gamma$-差基叔胺化 合物的高效 OKR 体系, 获得了光学活性的 $\gamma$-氨基醇类 产物(Scheme 2). 该课题组利用 $\mathrm{Ti}\left(\mathrm{O}^{i} \mathrm{Pr}\right)_{4}$ 与手性 $\mathrm{N}, \mathrm{O}$ 配 体配位形成双中心催化剂, 同时与底物中的羟基和氨基 配位，通过催化剂的调控让羟基官能团远离氨基，从而 使得不对称氧化选择性发生在氨基位置。该反应以 TBHP 作为氧化剂, 拆分系数 $s$ 最高可达 133, 回收的 $\gamma$ 氨基醇对映选择性最高可达 $99.4 \%$.
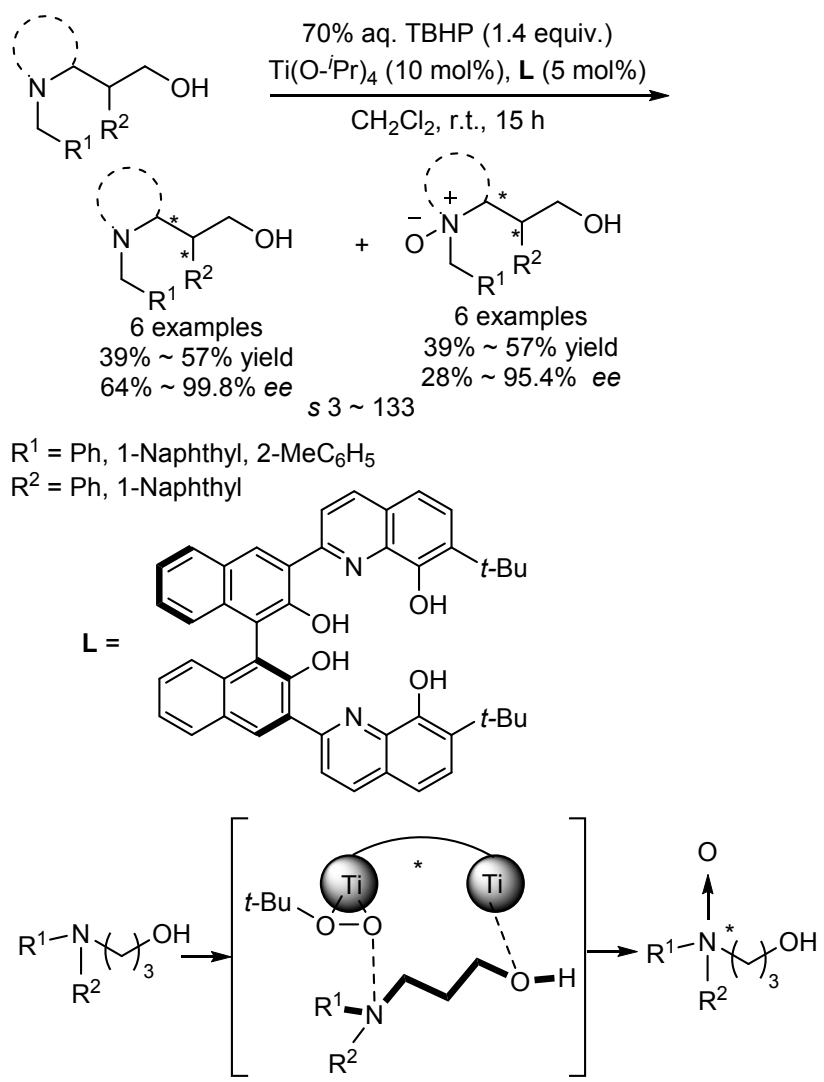

图式 2 钛催化的 $\gamma$-氨基醇氧化动力学拆分

Scheme 2 Ti-catalyzed OKR of $\gamma$-amino alcohols

最近几年，通过仲胺不对称脱氢形成亚胺从而实现 二级胺的 OKR 也有报道. 2013 年, Akiyama 课题组 ${ }^{[13]}$ 报 道了首例伯胺的高效 OKR, 他们利用不对称转移氢化 反应实现了二氢吲哚类化合物的氧化动力学拆分 (Scheme 3). 该课题组以手性磷酸为催化剂, 避免了过 渡金属催化剂因底物配位而失活的缺陷; 同时以酮亚胺 


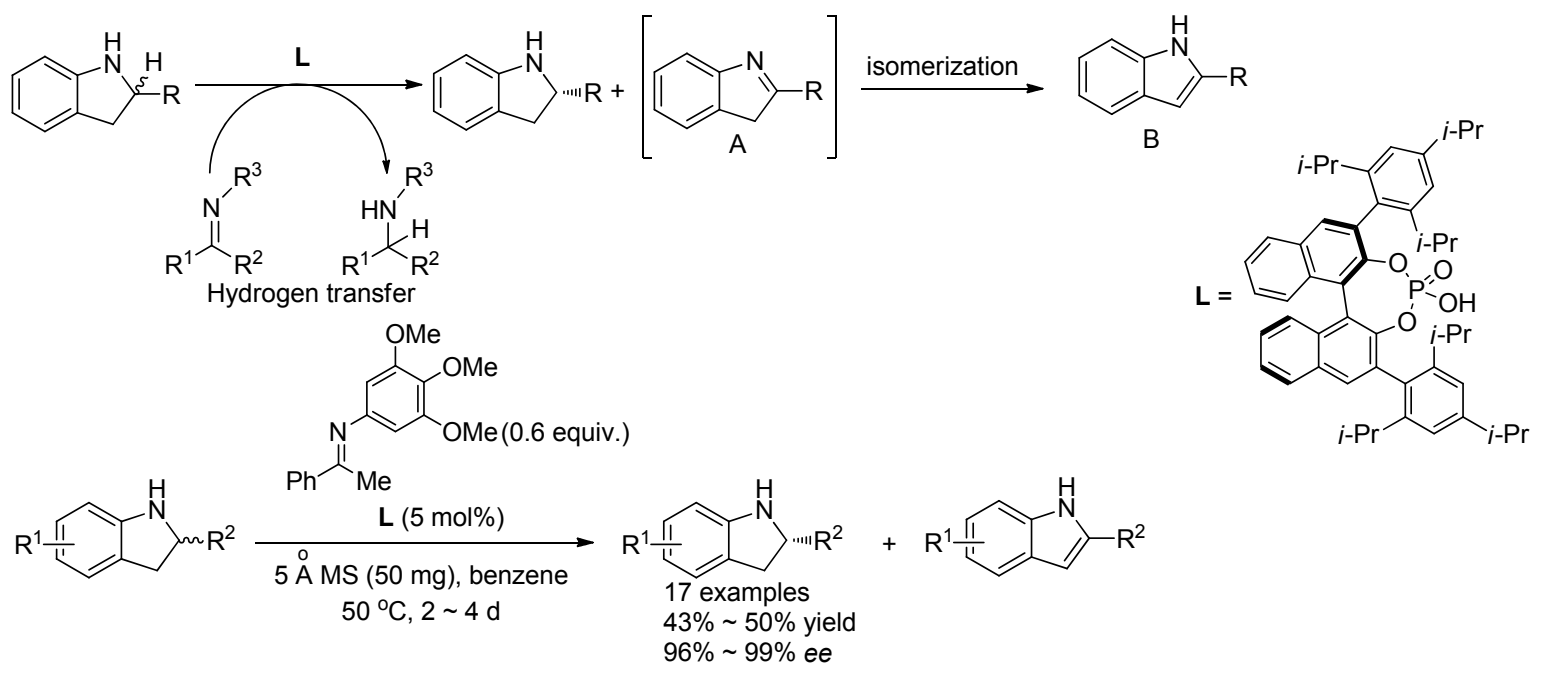

图式 3 手性磷酸催化的二氢吲哚氧化动力学拆分

Scheme 3 Chiral phosphoric acid-catalyzed OKR of indolines

为氢受体, 回收得到大于 $99 \% e e$ 的手性二氢吲哚原料, 而这些氮上无保护的 2 位芳基取代二氢吲哚类化合物使 用之前报道的不对称氢转移反应是无法合成的. 通过控 制实验，该课题组发现在标准反应条件下， $R$ 构型的底 物能被选择性氧化，而 $S$ 构型的底物基本没有反应.

2015 年, Akiyama 课题组 ${ }^{[13]}$ 利用相同的体系, 实现 了四氢喹啉及其衍生物的高效 OKR (Scheme 4). 该反 应体系对 2 位苯基类和直链烷基类底物都有很好的效 果, 特别是当取代基为正戊基时, 可回收 $98 \% \mathrm{ee}$ 的原 料, 拆分系数 $s$ 达到 458 . 当底物拓展到含有杂原子的四 氢喹啉类化合物时, 回收原料的对映选择性有了明显的 下降，例如原料含有 $\mathrm{S}$ 原子时，对映选择性只有 $73 \%$; 而底物环状结构的扩大也导致拆分效果明显下降, 对于 苯并氮杂草底物, 因为结构中含有七元环, 只能回收 $62 \%$ ee 的原料.

2016 年, Akiyama 课题组 ${ }^{[15]}$ 利用自氧化还原反应同 样实现了二氢吲哚类化合物的动力学拆分 (Scheme 5). 在该课题组 ${ }^{[13]}$ 之前报道的二氢吲哚的 OKR 反应中, 需 要加入酮亚胺作为氢受体, 但酮亚胺需要首先制备并保
存. 于是，该课题组考虑利用二氢吲哚与醛原位缩合生 成的亚胺作为氢受体, 通过分子内氢转移, 发生自氧化 还原反应来实现二氢吲哚的 OKR. 该反应依然以手性 磷酸作为催化剂, 可回收 $33 \% \sim 99 \% e e$ 的手性二氢吲哚 原料. 该反应体系对底物具有较好的官能团容忍性，并 且回收得到 $R$ 构型的二氢吲哚原料. 而之前该课题组使 用的 OKR 体系则得到 $S$ 构型的原料.

2019 年, 刘否课题组 ${ }^{[16]}$ 首次报道了利用 $\mathrm{O}_{2}$ 为氧化 剂, $\mathrm{Fe}$ 催化的环状仲胺的 OKR (Scheme 6), 将二级胺的 OKR 体系由小分子催化拓展到金属催化. 该反应以 4甲氧基-1-萗酚为添加剂, 在空气条件下即可实现环状 仲胺的高效 OKR，对映选择性最高可达 99\%. 对于 5,6二氢菲咯烷类底物, 苯环上取代基为供电子基时取得了 很好的效果; 对于 1,2-二氢喹啉类底物, 苯环上取代基 为供电子基或吸电子基都能得到很高的对映选择性. 通 过机理研究，该课题组发现添加剂 4-甲氧基-1-萗酚在 反应中起了重要的作用, 若没有添加剂, 则反应回收的 原料只有 $35 \% e e$; 单晶结构显示, 添加剂会与催化剂配 位, 形成新的催化剂结构, 从而提高反应的对映选择性.
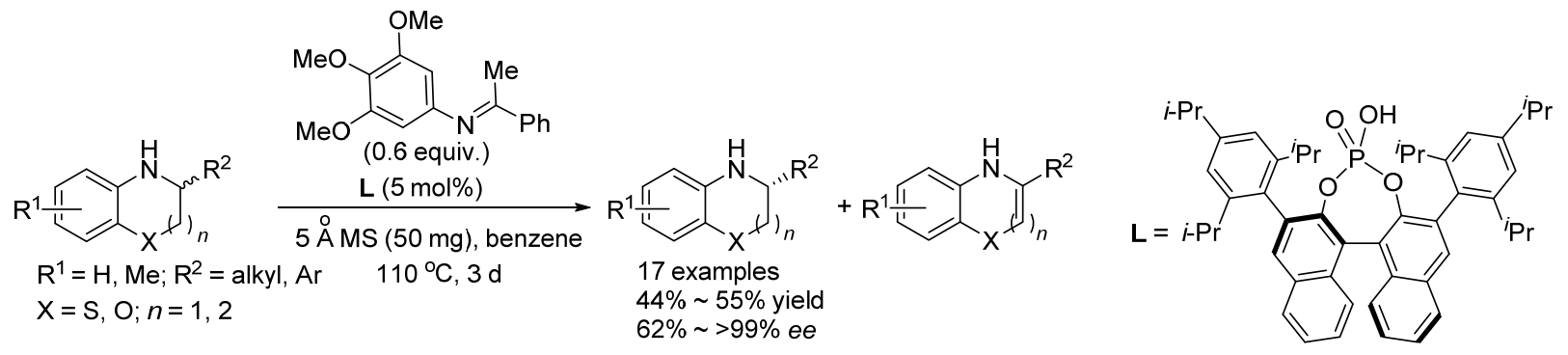

图式 4 手性磷酸催化的四氢喹啉及环状二级胺衍生物氧化动力学拆分

Scheme 4 Chiral phosphoric acid-catalyzed OKR of cyclic secondary amine derivatives including tetrahydroquinolines 


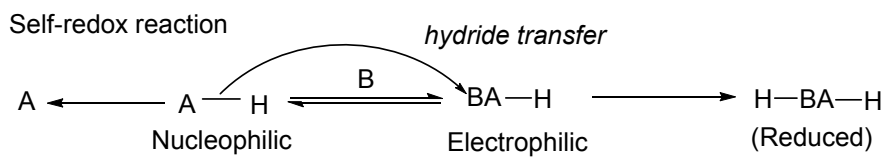

$\mathrm{KR}$ based on self-redox reaction

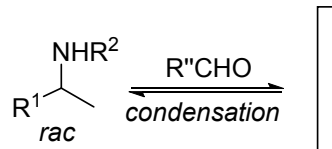

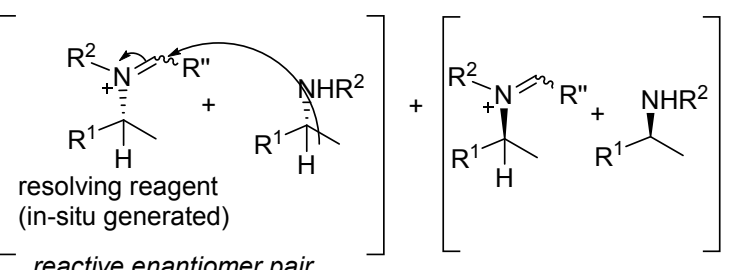

reactive enantiomer pair cat.* $\downarrow \begin{gathered}\text { Intermolecular } \\ \text { hydride transfer }\end{gathered}$<smiles>[R]CN([R])C([R])([R])C</smiles><smiles>COc1ccc(OCC(C)(C)C)c(C=O)c1</smiles><smiles>[R]C(C)N(CC)[R]([H])([H])[H]</smiles>

图式 5 手性磷酸催化的二氢吲哚自氧化还原动力学拆分

Scheme 5 Chiral phosphoric acid-catalyzed self-redox KR of indolines<smiles>[R]c1ccccc1-c1ccccc1N</smiles>

$\mathrm{R}^{1}=\mathrm{Me}, \mathrm{OMe}, \mathrm{Cl}$ $\mathrm{R}^{2}=$ aryl, alkyl, benzyl $\mathrm{R}^{3}=\mathrm{Me}, \mathrm{OMe}$<smiles>[R1]C=C1C=CC=C2NC([R])C=C([R])C12</smiles>

$\mathrm{R}^{1}=\mathrm{F}, \mathrm{Cl}, \mathrm{Br}, \mathrm{Me}$

$\mathrm{R}^{2}=$ aryl, $\mathrm{Me}$ $\mathrm{R}^{3}=\mathrm{H}, \mathrm{Me}$<smiles>[R]C1C[R]2cccc2C2=C(C=C[R1]C=C2)N1</smiles>

20 examples $44 \% \sim 48 \%$ yield $90 \% \sim 99 \%$ ee<smiles>[R]c1nc2cc[Y10]([I-])cc2c2ccc[R]c12</smiles><smiles>COc1ccc(O)c2ccccc12</smiles>
C5 (2.5 mol\%) air, toluene, $1 \sim 7 \mathrm{~h}$<smiles>[R]C1=CC([R])Nc2c[R1]ccc21</smiles>

13 examples $40 \% \sim 49 \%$ yield $88 \% \sim 98 \%$ ee<smiles>[R]c1cc([R1])c2c[R1]ccc2n1</smiles><smiles></smiles>

C5

图式 6 铁催化的环状仲胺的氧化动力学拆分

Scheme 6 Iron-catalyzed OKR of cyclic secondary amines

\section{2 氮杂环丙烷开环动力学拆分及 $2 H$-氮杂丙烯啶的 加成动力学拆分}

氮杂环丙烷是一类具有生物活性的三元杂环化合 物, 许多天然产物中含有氮杂环丙烷结构, 它们具有抗 病毒、抗肿瘤的生物活性 ${ }^{[17]}$. 当氮杂环丙烷中氮原子上
连有磺酰基、酰基或膦酰基等吸电子取代基时，会降低 三元环上的电子云密度，更容易受到亲核试剂的进攻， 在开环反应中表现出较高的活性，从而合成含有不同官 能团的胺、氨基酸和氨基硫醇等化合物. 因此, 利用氮 杂环丙烷的不对称开环反应实现胺的动力学拆分越来 
越受到化学家的关注.

2012 年, Morgan 课题组 ${ }^{[18]}$ 报道了利用手性 BINOL 和氮杂环丙烷的不对称开环反应实现氮杂环丙烷动力 学拆分的例子(Scheme 7). 该反应以 $\mathrm{B}(\mathrm{OPh})_{3}$ 作为 Lewis 酸催化剂, 避免了 $N$-DNB 氮杂环丙烷重排生成噁唑啉 的副反应, 并可回收最高 $99.4 \% e e$ 的 $R$ 构型原料, 拆分 系数 $s$ 最高可达 255. 空间位阻增大导致该反应拆分效 果明显下降, 例如, $\mathrm{R}^{1}$ 基团为叔丁基时，只得到对映选 择性为 $5.6 \%$ 的产物, 拆分系数 $s$ 则只有 2 .

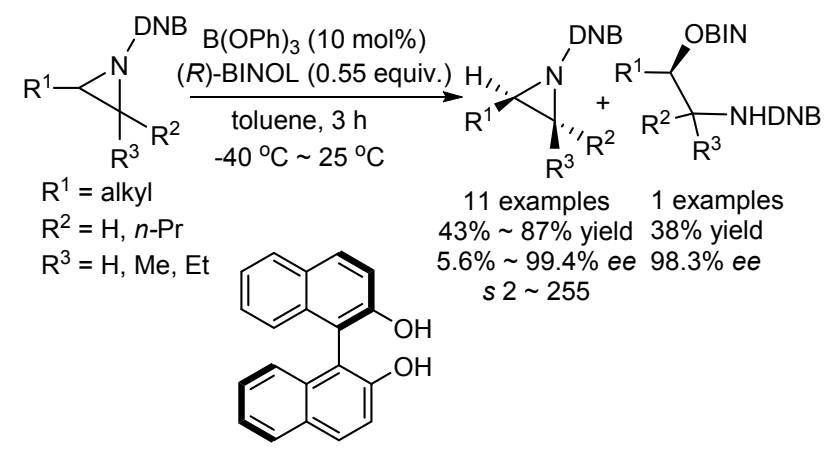

(R)-BINOL

图式 $7 \mathrm{~B}(\mathrm{OPh})_{3}$ 催化的氮杂环丙烷的动力学拆分

Scheme $7 \quad \mathrm{~B}(\mathrm{OPh})_{3}$-catalyzed $\mathrm{KR}$ of aziridines

2012年, Ooi课题组 ${ }^{[19]}$ 报道了有机小分子催化的氮杂环 丙烷的不对称开环动力学拆分 (Scheme 8). 该课题组使 用手性氯化 1,2,3-三唑鎓盐为催化剂, $\mathrm{Me}_{3} \mathrm{SiOH}$ 为添加剂, 利用 $\mathrm{Me}_{3} \mathrm{SiCl}$ 为亲核试剂对2-取代氮杂环丙烷底物进行 不对称开环反应, 实现了2-取代氮杂环丙烷
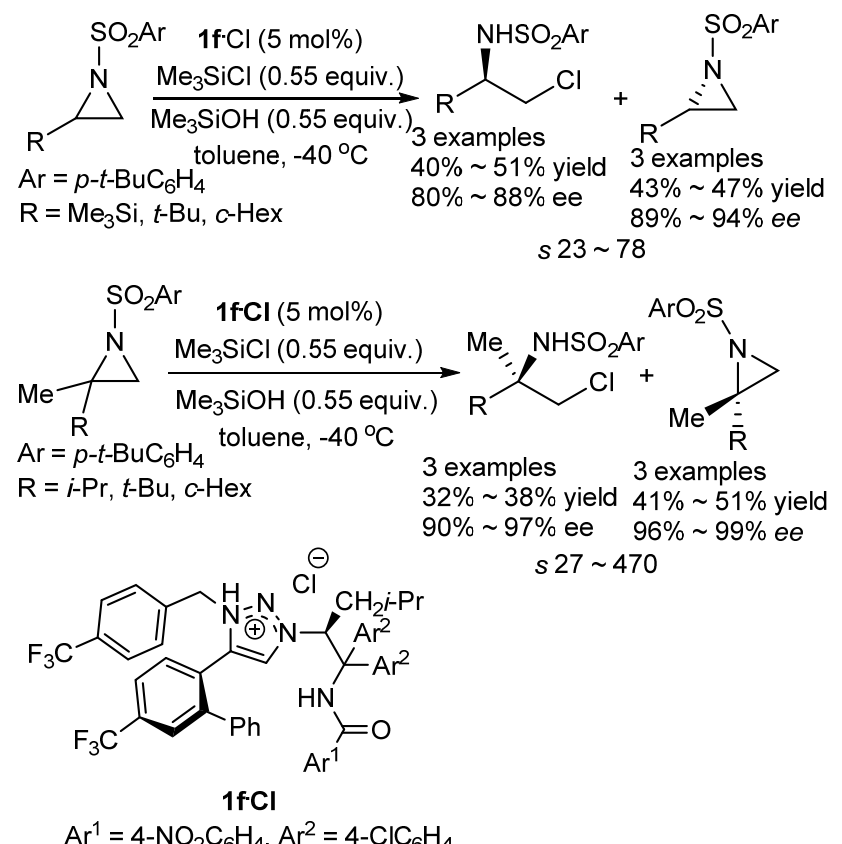

$s 27 \sim 470$

图式 8 小分子催化的 2-取代氮杂环丙烷的动力学拆分

Scheme 8 Organocatalyzed KR of 2-substituted aziridines
类化合物的动力学拆分. 该课题组研究发现，使用 2-取 代氮杂环丙烷为反应底物，回收得到大于 $89 \%$ ee 手性 氮杂环丙烷原料的同时得到产物 $\beta$-氯 $\alpha$ 仲胺, 此时的产 物没有区域选择性; 然而当底物为 2,2-取代氮杂环丙烷 时，回收大于 $96 \%$ ee 手性氮杂环丙烷原料的同时开环 产物会出现区域选择性，得到两种化合物，其中主要产 物为 $\beta$-氯- $\alpha$-叔胺, 对映选择性最高达 $97 \%$.

2013 年, Ooi 课题组 ${ }^{[20]}$ 继续对 2,2-二取代氮杂环丙 烷类化合物的动力学拆分进行研究, 发现当使用 3-取代 氧化吲哚作为亲核试剂，可以同时获得高对映选择性和 高区域选择性的产物(Scheme 9). 该反应使用手性溴化 1,2,3-Triazolium 盐为催化剂, 当取代基为 2-Naphthyl 时, 可获得 99\% ee, $d r$ 大于 20: 1 的开环产物，并回收 76\% $e e$ 的 2,2-二取代氮杂环丙烷原料, 拆分系数 $s$ 为 17 .
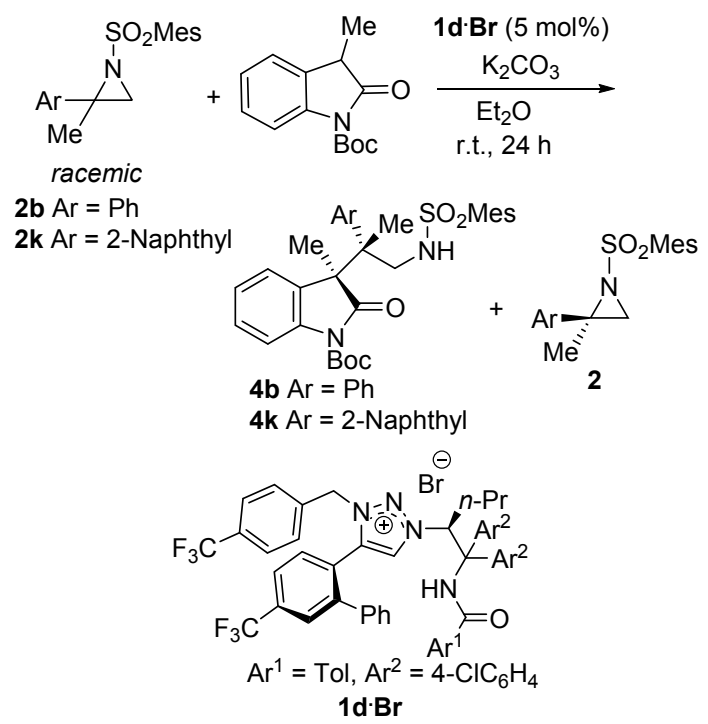

4b: $99 \%, d r>20: 1,99 \%$ ee, 2b: $99 \%$ recovery, $76 \%$ ee, $s=17$ 4k: $97 \%, d r>20: 1,99 \%$ ee, 2k: $99 \%$ recovery, $76 \%$ ee, $s=17$

图式 9 小分子催化的 2,2-二取代氮杂环丙烷的动力学拆分 Scheme 9 Organocatalyzed KR of 2,2-disubstituted aziridines

2014 年, List 课题组 ${ }^{[21]}$ 报道了手性磷酸催化的端位 氮杂环丙烷的不对称开环动力学拆分 (Scheme 10), 该 课题组使用苯甲酸作为亲核试剂, 可实现 2-取代氮杂环 丙烷的高效拆分, 拆分系数 $s$ 最高可达 51. 该反应体系 中底物的取代基为长链烷基和环烷基.

2015 年, 柴卓课题组 ${ }^{[22]}$ 报道了利用不对称 $[3+2]$ 环 加成反应实现氮杂环丙烷动力学拆分的例子(Scheme $11)$. 该课题组以 $\mathrm{Cu}\left(\mathrm{CH}_{3} \mathrm{CN}\right)_{4} \mathrm{BF}_{4}$ 为金属, $R$-xylBINAP 为手性配体, 通过氮杂环丙烷与吲哚类化合物的不对称 $[3+2]$ 环加成反应实现了 $N-T s$ 氮杂环丙烷类底物的动 力学拆分. 对于 2 位取代基为 2-菜基的底物. 得到对映 选择性为 $93 \%$ 的环加成产物，并回收对映选择性为 $93 \%$ 的原料，拆分系数 $s$ 为 60 . 


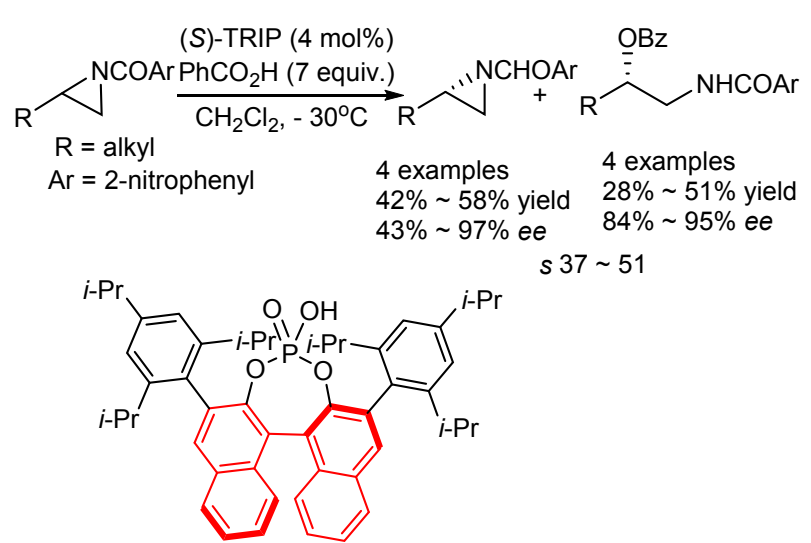

(S)-TRIP

图式 10 手性磷酸催化的氮杂环丙烷动力学拆分

Scheme 10 Chiral phosphoric acid-catalyzed KR of aziridines

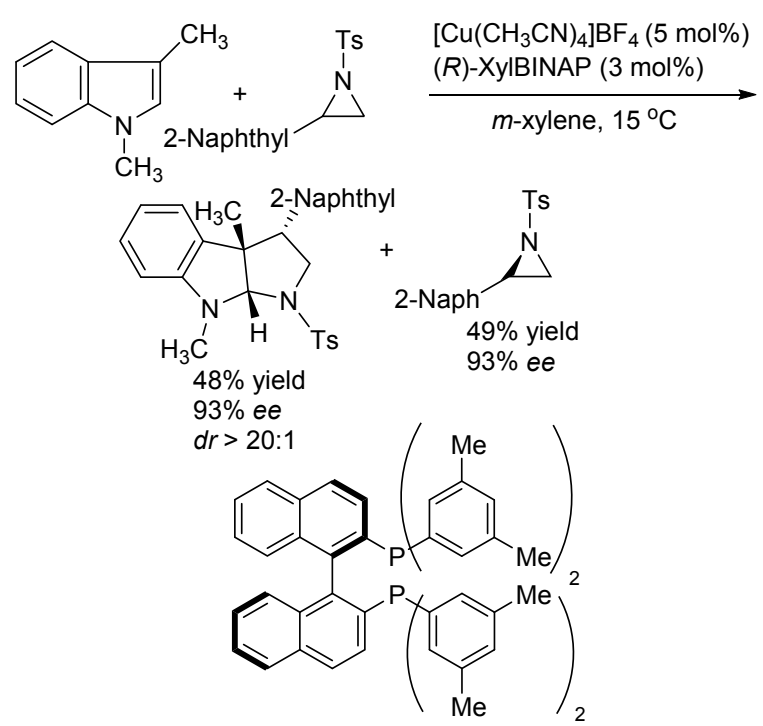

$(R)$-XyIBINAP

图式 11 铜催化的 $N-T s$ 氮杂环丙烷动力学拆分

Scheme 11 Cu-catalyzed KR of $N$-Ts aziridines

2017 年, 柴卓课题组 ${ }^{[23]}$ 继续报道了以胺作为亲核 试剂实现氮杂环丙烷不对称开环动力学拆分的例子 (Scheme 12). 该课题组发现, 当使用 $\mathrm{Ag}$ 为金属, $\mathrm{PMPNH}_{2}$ 作为亲核试剂时, 可实现两 2 位取代的 $N$-Ts 氮 杂环丙烷的动力学拆分, 拆分系数 $s$ 最高可达 53. 同时, 对于 2 位取代基为 $\mathrm{Ph}$ 的底物, 可实现克级规模的动力学 拆分.

2019 年, 冯小明课题组 ${ }^{[24]}$ 报道了以颈基苯并噻唑 作为亲核试剂, $\mathrm{La}(\mathrm{OTf})_{3} / L-\mathrm{RaMe}_{2}$ 配合物为手性催化剂, 实现 1,2-二取代氮杂环丙烷动力学拆分的例子. 该反应 拆分系数 $s$ 最高达 61 (Scheme 13). 该课题组通过改变 溶剂的用量, 成功实现了克级规模原料的动力学拆分, 并且得到了良好的效果.

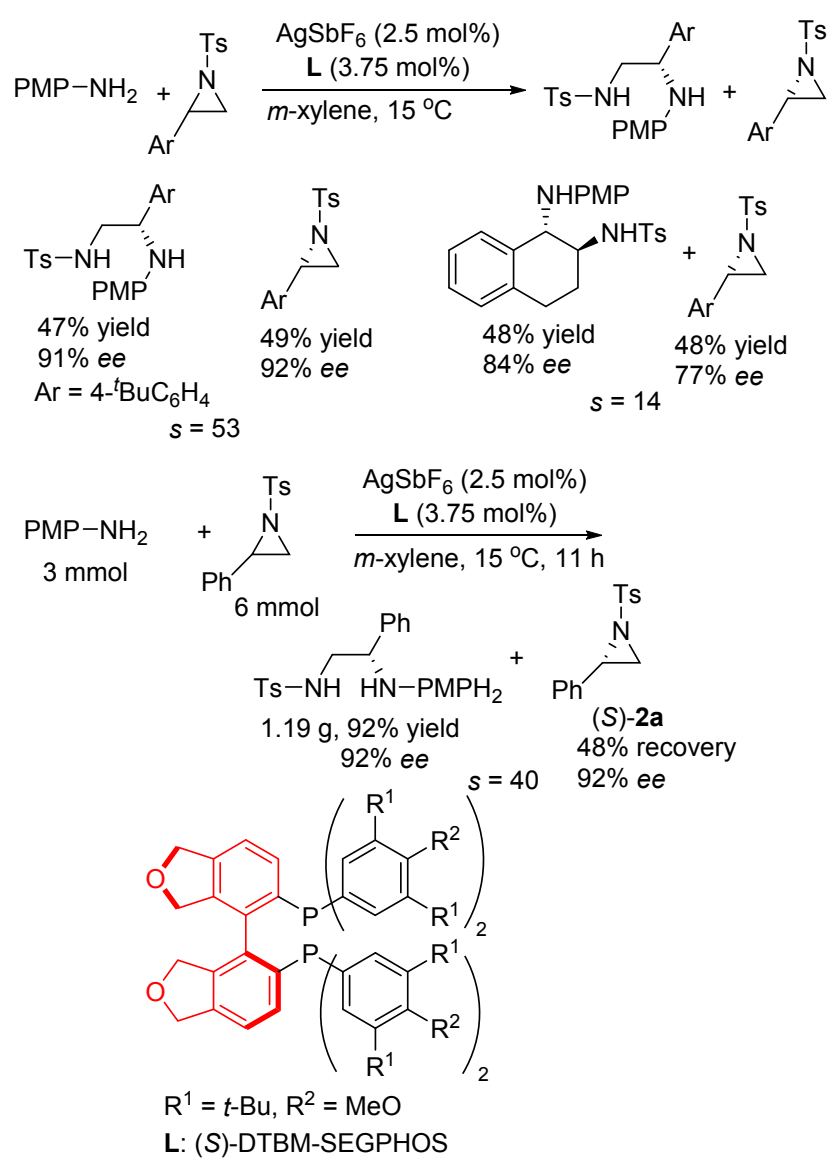

图式 12 银催化的 $N-T s$ 氮杂环丙烷动力学拆分

Scheme 12 Ag-catalyzed KR of NTs aziridines
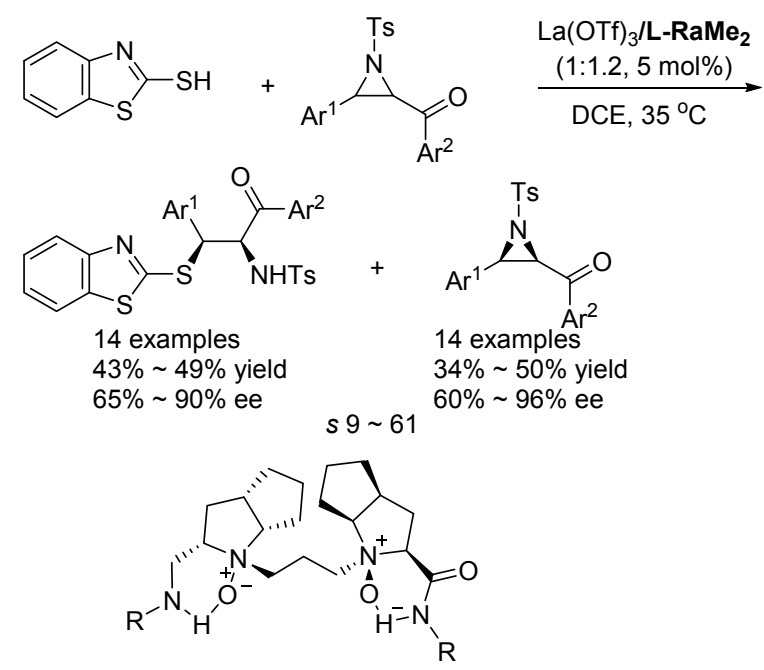

L-RaMe $2: R=2,6-\mathrm{Me}_{2} \mathrm{C}_{6} \mathrm{H}_{3}$

图式 13 镧催化的 $N-T s$ 氮杂环丙烷动力学拆分

Scheme 13 La-catalyzed KR of $N$-Ts aziridines

平行动力学拆分(Parallel Kinetic Resolution)是指两 个具有互补立体选择性的手性试剂 $\mathrm{B}^{*}$ 和 $\mathrm{E}^{*}$, 与消旋底 物的 $S$ 构型 $\left(\mathrm{A}_{S}\right)$ 和 $R$ 构型 $\left(\mathrm{A}_{R}\right)$ 分别反应得到两个非对映 产物 $\mathrm{D}$ 和 $\mathrm{F}$ ，从而实现底物构型分离的方法. 在同样的 
反应条件下, $S$ 构型 $\left(\mathrm{A}_{S}\right)$ 和 $R$ 构型 $\left(\mathrm{A}_{R}\right)$ 具有相近的反应活 性 $\left(k_{S} \approx k_{R}\right)$, 但立体选择性相反; 而在整个反应过程中, $\mathrm{A}_{S}$ 和 $\mathrm{A}_{R}$ 的浓度基本相同, 从而能同时得到两种高产率 与高对映选择性的产物(Scheme 14) ${ }^{[25]}$.

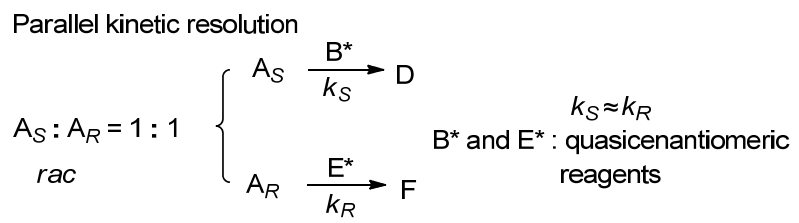

图式 14 平行动力学拆分

Scheme 14 Parallel Kinetic Resolution

2009 年 RajanBabu 课题组 ${ }^{[26]}$ 报道了 Y 催化的氮杂 环丙烷的开环平行动力学拆分的例子 (Scheme 15). 该 课题组以 $\mathrm{TMSN}_{3}$ 为亲核试剂, $\mathbf{1 0 b}$ 为手性催化剂, 在 1,2-二氯乙烷条件下室温反应 2 6 h, 即可实现 2-烷基 取代氮杂环丙烷的高效平行动力学拆分, 得到两种 $R$ 构 型的酰胺产物, 对映选择性最高可达 99\%. 2014 年, 该 课题组的机理研究表明, $R$ 构型的底物在催化条件下, $\mathrm{TMSN}_{3}$ 进攻 3 位; $S$ 构型的底物在催化条件下, $\mathrm{TMSN}_{3}$ 进攻 2 位 ${ }^{[27]}$.
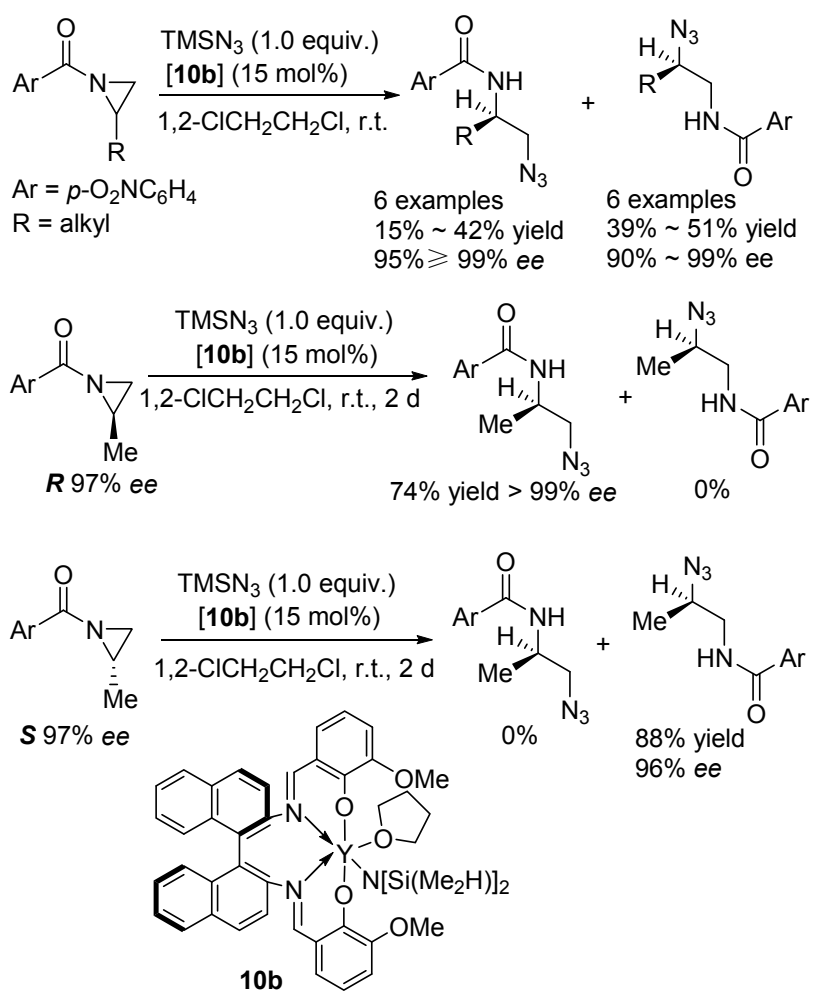

图式 15 钎催化的氮杂环丙烷的平行动力学拆分

Scheme 15 Y-catalyzed PKR of aziridines

2014 年 Shibasaki 课题组 ${ }^{[28]}$ 报道了以丙二酸酯类化 合物为亲核试剂实现氮杂环丙烷平行动力学拆分的例
子(Scheme 16). 该课题组以双核手性席夫碱为手性配 体，以 $\mathrm{La}$ 和 $\mathrm{Y}$ 作为双核金属，通过丙二酸酯对氮杂环丙 烷的区域选择性不对称开环实现了 $N$-酰基氮杂环丙烷 的平行动力学拆分, 得到大于 $98 \% e e$ 的两个产物, 并且 当底物由 2 取代拓展为 2,3 -二取代时，拆分效果依然很 好.

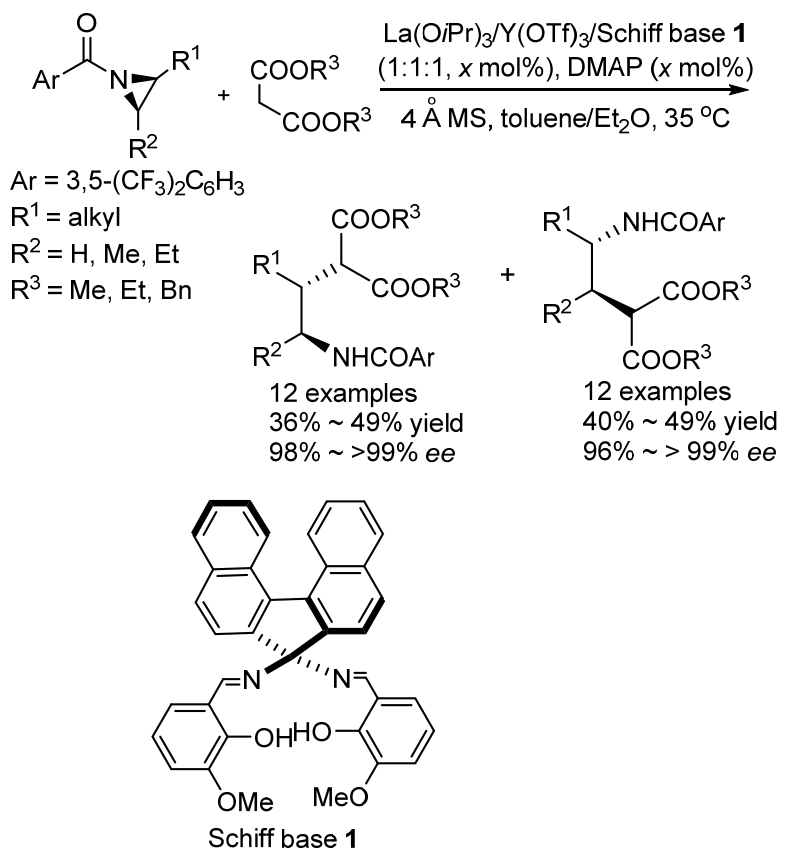

图式 16 镧/钎共催化的氮杂环丙烷平行动力学拆分 Scheme $16 \mathrm{La} / \mathrm{Y}$-cocatalyzed PKR of aziridines

$2 H$-氮杂丙烯啶是合成氮杂环丙烷的重要前体，通 过亲核试剂对 $2 H$-氮杂丙烯啶的不对称加成可以合成各 种类型的手性氮杂环丙烷化合物. 2016 年, Feng 课题 组 ${ }^{[29]}$ 报道了利用 $\mathrm{Sc}$ 催化的 $2 H$-氮杂丙烯啶不对称加成 动力学拆分获得手性氮杂环丙烷和手性 $2 H$-氮杂丙烯啶 的例子(Scheme 17). 该课题组以吲哚酮作为亲核试剂. 以 $\mathrm{Sc}(\mathrm{OTf})_{3} / L-\mathrm{RaPr}_{2}$ 配合物为手性催化剂, 可以取得优 异的拆分结果, 拆分系数 $s$ 最高达 790. 与之前文献报道 不同的是, 亲核反应发生在吲哚酮亲核性较弱的 1 位氮 原子而不是 3 位碳原子, 该反应体系对底物官能团容忍 性较高, 不管 $\mathrm{R}^{1}$ 是芳基还是烷基, 都能给出优秀的结 果; 同时, $\mathrm{R}^{2}$ 基团芳环上的吸电子基和供电基都不影响 效率.

2016 年. 张锁秦课题组 ${ }^{[30]}$ 报道了利用吡唑类化合 物对 $2 H$-氮杂丙烯啶的不对称加成, 从而实现 $2 H$-氮杂 丙烯啶动力学拆分的例子(Scheme 18). 该课题组利用 手性磷酸作为催化剂. 以 3 位取代基为 4-溴苯基的吡唑 酸乙酯为亲核试剂, 可选择性对 $(S)-2 H$-氮杂丙烯啶羧酸 酯加成, 从而实现 $2 H$-氮杂丙烯啶的动力学拆分, 得到 高对映选择性的产物和原料. 拆分系数 $s$ 最高可达到 


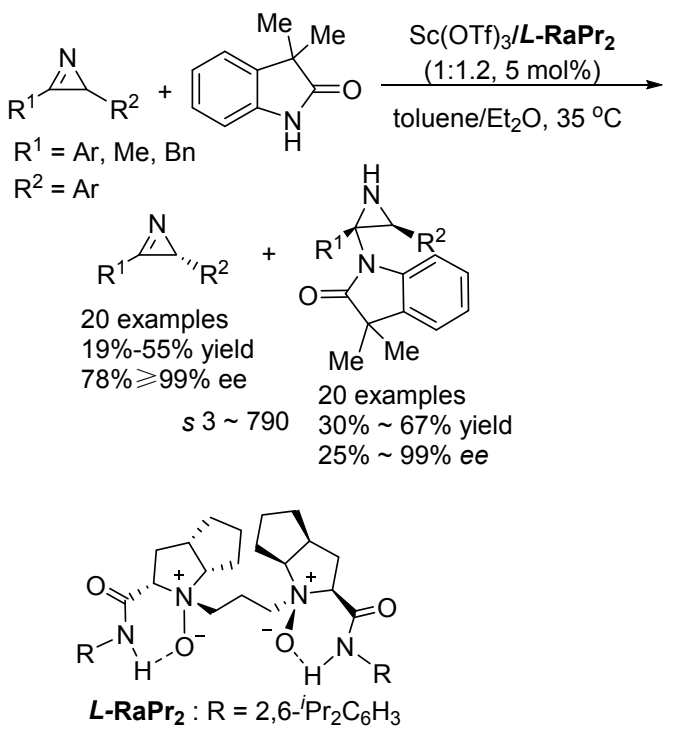

图式 17 锌催化的 $2 H$-氮杂丙烯啶加成动力学拆分

Scheme 17 Sc-catalyzed KR of $2 H$-azirines<smiles>[R20]OC(=O)C1N=C1[Z17](=O)OCC</smiles><smiles>[R2]OC(=O)[C@@H]1NC1[R10]</smiles>

$\mathrm{R}^{1}=\mathrm{alkyl}, \mathrm{Ar}$

$\mathrm{R}^{2}=\mathrm{Me}, \mathrm{Et}, i-\mathrm{Pr}, \mathrm{Bn} \quad s 55 \sim 1057$

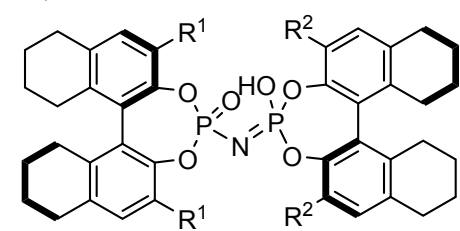

4a, $R^{1}=R^{2}=1$-naphthyl

图式 18 手性磷酸催化的 $2 H$-azirine 动力学拆分 Scheme 18 Chiral phosphoric acid-catalyzed KR of $2 \mathrm{H}$-azirines 1051.

\section{3 取代反应动力学拆分}

不对称烯丙基取代反应是通过碳一碳和碳-杂原子 成键从而构建手性中心的强有力方法. 目前, 将不对称 烯丙基取代应用于胺类化合物的拆分也有了报道. 2009 年, 侯雪龙课题组 ${ }^{[31]}$ 报道了利用钯催化的不对称烯丙 基取代反应实现二氢吲哚类化合物动力学拆分的例子 (Scheme 19). 该反应利用手性 P,N 类配体, 以烯丙基 Boc 酯为亲电试剂, 在室温条件下即可实现二氢吲哚类 化合物的动力学拆分. 该反应体系对 2-芳基二氢吲哚底
物有较好的拆分效果，特别是取代基为对甲氧基苯基 时，可得到 $92 \% e e$ 的产物并回收 $80 \% e e$ 的原料，拆分 系数 $s$ 可达 59. 然而，当 2 位取代基为烷基时，拆分效 果很差, 拆分系数 $s$ 小于 10 ; 同时, 对于四氢喹啉类化 合物，拆分结果同样不好.

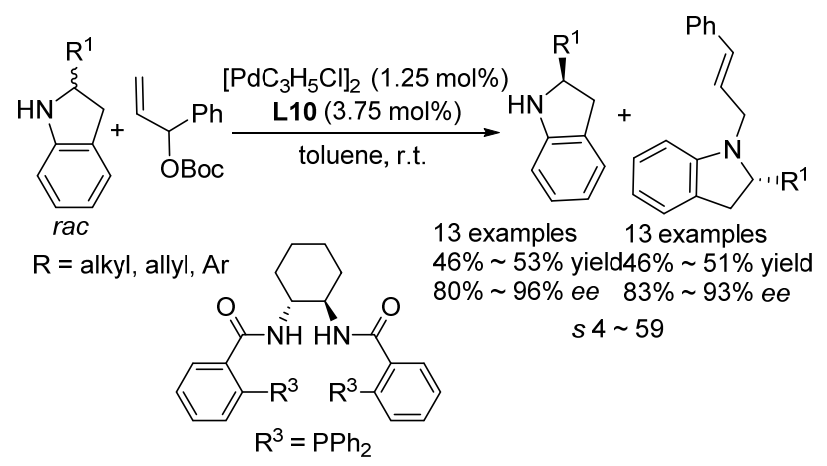

图式 19 钯催化的二氢吲哚烯丙基取代动力学拆分 Scheme 19 Pd-catalyzed asymmetric allylic amination KR of indolines

2015 年, 田仕凯题组 ${ }^{[32]}$ 报道了利用钯催化不对称 烯丙基烷基化反应实现了一级烯丙基胺的动力学拆分 的例子 (Scheme 20). 该课题组 ${ }^{[33]}$ 之前研究了磺酰肼与 一级烯丙基胺的氧化偶联反应，并提出了磺酰胇加速一 级烯丙基胺烯丙基烷基化的可能机理. 于是, 该课题组 将磺酰肼应用于一级烯丙基胺的动力学拆分中，以提高 拆分反应的活性，并取得了良好的效果. 该课题组利用 手性 BINAP 作为配体，在空气下反应，即实现了一级烯 丙基胺的高效动力学拆分, 拆分系数 $s$ 最高可到 491, 但 是该反应体系的底物受限于芳基取代的烯丙基胺.

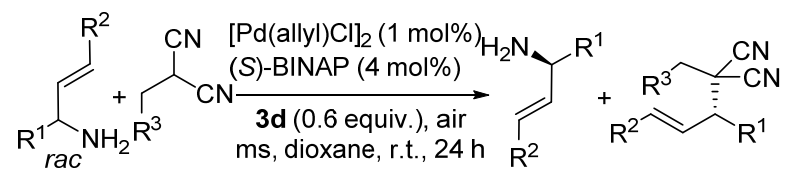

$\mathrm{R}^{1}=$ alkyl, alkenyl, $\mathrm{Ph} \quad 21$ examples 21 examples $\mathrm{R}^{2}=\mathrm{H}, \mathrm{c}$-Hex, $\mathrm{Ar}$, alkenyl $\quad 41 \% \sim 56 \%$ yield $21 \% \sim 57 \%$ yield $\mathrm{R}^{3}=\mathrm{Ph}, 2$-furyl, CCTMS, $\mathrm{CO}_{2} t-\mathrm{Bu} \quad 70 \% \sim 99 \%$ ee $\quad 46 \% \sim 99 \%$ ee $s 5.4 \sim 491$

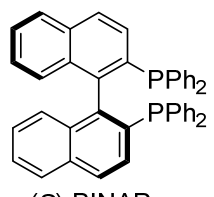

$2,4,6-\mathrm{Me}_{3} \mathrm{C}_{6} \mathrm{H}_{2} \mathrm{SO}_{2} \mathrm{NHNH}_{2}$

$3 d$
图式 20 钯催化烯丙基胺的烯丙基烷基化动力学拆分 Scheme 20 Pd-catalyzed asymmetric allylic alkylation KR of primary allylic amines

2009 年, 田仕凯课题组 ${ }^{[34]}$ 报道了硫醇作为亲核试 剂与 $N$-芳基磺胺类化合物的偶联反应(Scheme 21). 2012 年, 该课题组 ${ }^{[35]}$ 利用手性磷酸实现了硫醇对 $N-(3$ - 吲哚 基)(苯基)甲基磺胺类化合物的不对称亲核取代动力学 
拆分 ${ }^{[35]}$. 该反应体系在温和条件下进行, 并且拆分效果 很好, 回收的 $N$-(3-吲哚基)(苯基)甲基磺胺类原料对映 选择性大于 $90 \%$. 当底物拓展到叔胺类化合物时, 依然 能得到很高的对映选择性, 但是当 3-吲哚基的 NH 基团 被 $\mathrm{NCH}_{3}$ 基团取代时, 反应效果很差, 回收原料的对映 选择性只有 $15 \%$, 表明 $\mathrm{NH}$ 基团是实现该类化合物高效 动力学拆分的基本骨架.

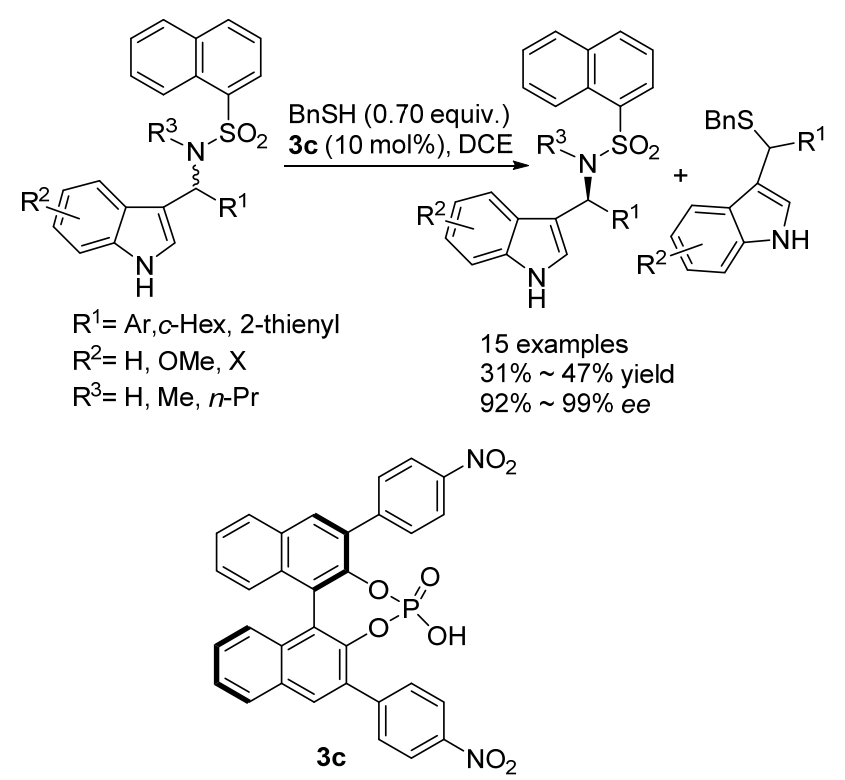

图式 21 手性磷酸催化的 $N$-芐基磺胺取代动力学拆分 Scheme 21 Chiral phosphoric acid-catalyzed KR of $N$-benzylic sulfonamides

\section{$1.4 \mathrm{C}$-X 活化动力学拆分法}

碳卤活化是重要的有机合成方法, 并且在有机合成 中得到了广泛的应用. 近年来, 将不对称碳氢活化及碳 卤活化应用于胺的动力学拆分也有了一些研究. 2013 年, Cai 课题组 ${ }^{[36]}$ 报道利用 $\mathrm{C}-\mathrm{I}$ 活化, 通过分子内的不 对称 $\mathrm{N}$ 芳基化, 实现了 $\alpha$ 叔胺类化合物的动力学拆分 (Scheme 22). 该课题组利用 $\mathrm{CuI}$ 作为催化剂, 手性 BINOL 衍生物作为配体, 在温和条件下快速地实现了 2-氨基-3-(2-碘代芳基)丙酸酯类叔胺化合物的动力学拆 分, 以高对映选择性回收原料的同时也得到了高对映选 择性的具有季碳手性中心的二氢吲哚类产物, 拆分选择 系数 $s$ 最高可达 91.3. 该课题组将底物扩展到 2-氨基 -4-(2-碘代芳基)丁酸酯类化合物时，同样得到了很好的 拆分结果. 四氢喹啉类产物对映选择性最高可达 $97 \%$, 拆分系数 $s$ 最高可达 245 .

\section{5 其它反应的动力学拆分}

2008 年, Enders 课题组 ${ }^{[37}$ 报道了手性磷酰胺催化的 芐胺的立体化学消融动力学拆分(Scheme 23). 该反应 只有当 $\mathrm{R}$ 基团为 3-丙烯酸甲酯基时动力学拆分才能实
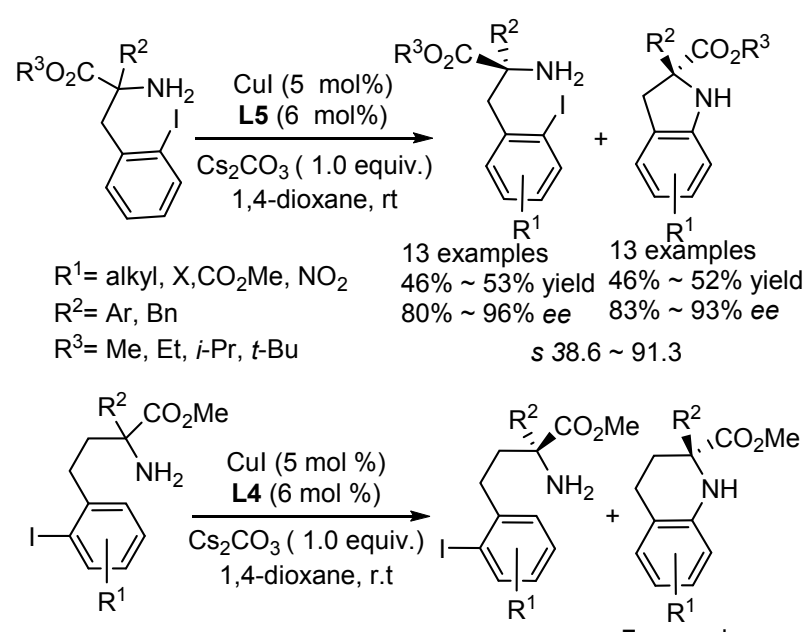

$\mathrm{R}^{1}=\mathrm{H}, \mathrm{Me}, \mathrm{Cl}$

$\mathrm{R}^{2}=$ alkyl, $\mathrm{Ar}$

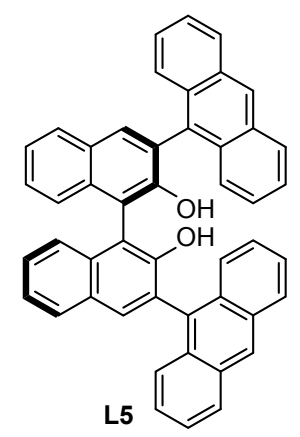

7 examples 7 examples $46 \% \sim 51 \%$ yield $45 \% \sim 50 \%$ yield $85 \% \sim 90 \%$ ee $\quad 80 \% \sim 97 \%$ ee $s 28 \sim 245$

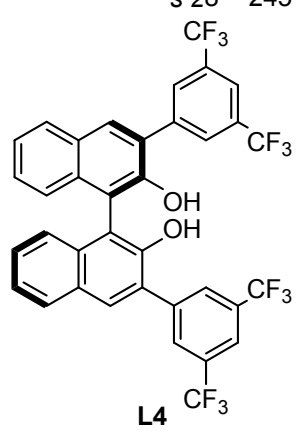

图式 22 铜催化的不对称 C-I 活化动力学拆分 Scheme 22 Cu-catalyzed C-I activation KR

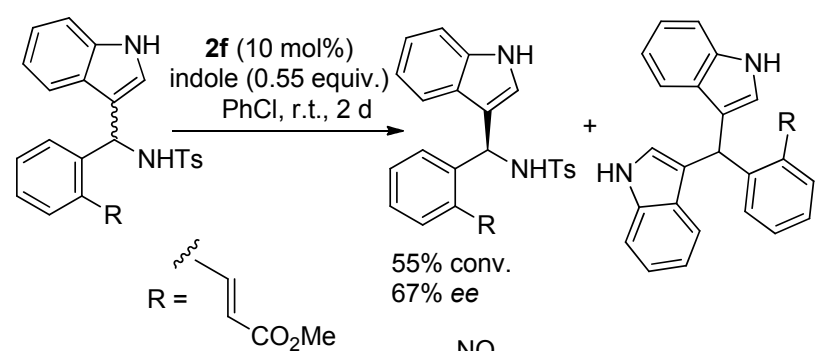<smiles>CCNP1(=O)Oc2c(-c3ccc([N+](=O)[O-])cc3)cc3ccccc3c2-c2c(-c3ccc([N+](=O)[O-])cc3)cc3ccccc3c2O1</smiles>

图式 23 手性磷酰胺催化的立体消融动力学拆分 Scheme 23 Chiral phosphoric amide-catalyzed stereoablative KR

现，并可获得 $67 \%$ ee 的手性苄胺原料.

2009 年, Hultzsch 课题组 ${ }^{[38]}$ 报道了稀土金属催化的 $\gamma$-氨基- $\gamma$-取代烯烃化合物的氢胺化动力学拆分 (Scheme 24). 该反应使用手性双酚和联菜酚作为配体，通过 $\gamma$-氨 
基- $\gamma$-取代烯烃的分子类不对称氢胺化反应实现了动力 学拆分, 得到了非对映选择性(反式/顺式高达 50:1)的 环状胺类化合物, 并回收了中等到良好对映选择性的原 料, 拆分系数 $s$ 最高达 19. 该研究发现, 随着烷基取代 基的空间位阻增加，含有脂肪族取代基的底物拆分效果 不断下降, 产物的反/顺一非对映选择性增加; 当底物由 $\gamma$-氨基- $\gamma$-取代烯烃拓展到 $\gamma$-氨基- $\beta$-取代烯烃时, 其拆分 效果同样下降，产物的反/顺-非对映选择性小于 $2: 1$, 回收的原料对映择性也很差.

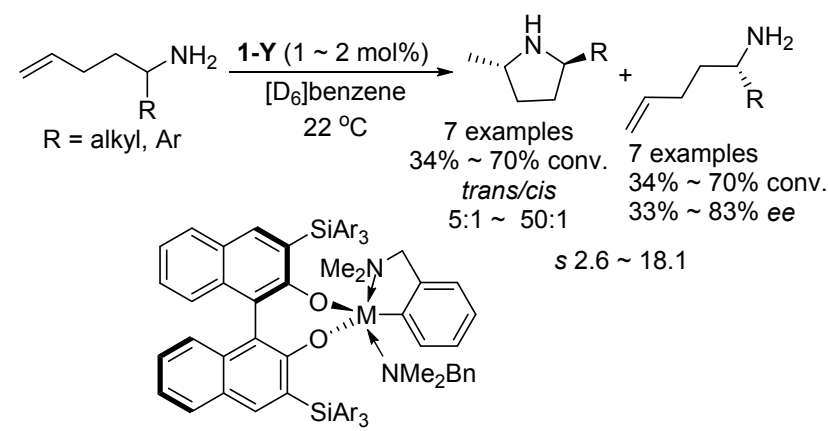

(R)-1-Ln: $\mathrm{Ar}=\mathrm{Ph}$

(R)-2-Ln: $\mathrm{Ar}=3,5-\mathrm{Me}_{2} \mathrm{C}_{6} \mathrm{H}_{3}$ $\mathrm{Ln}=\mathrm{Sc}, \mathrm{Y}, \mathrm{Lu}$

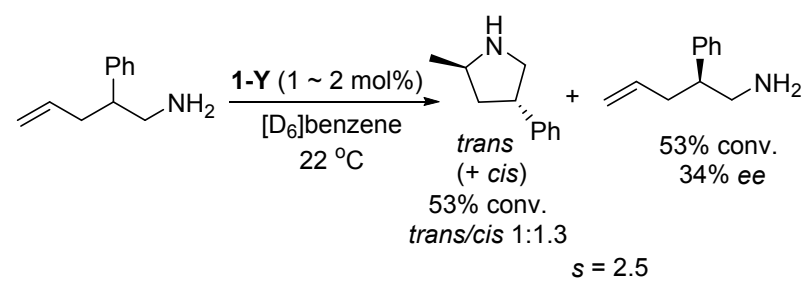

图式 24 稀土金属催化的烯胺化合物不对称氢胺化动力学拆 分

Scheme 24 Ln-catalyzed asymmetric hydroamination KR of aminoalkenes

2008 年游书力课题组 ${ }^{[39]}$ 报道了手性 $\mathrm{NHC}$ 催化的 $\beta$ 内酰胺的扩环动力学拆分的例子(Scheme 25). 该小组 利用 $\beta$ 内酰胺的扩环反应实现了 $c i s-4$-甲酰基- $\beta$ 内酰胺 的高效动力学拆分, 回收的 $c i s-4$-甲酰基- $\beta$-内酰胺对映 选择性最高可达到 $99 \%$, 但是该反应的产物对映选择性 很低.

2013 年冯小明课题组 ${ }^{[40]}$ 报道了通过有机小分子催 化的不对称氧化胺化实现氧杂吅丙啶类化合物的动力 学拆分的例子(Scheme 26). 该课题组利用鲐内酯底物 的多位点反应性, 通过唤酯的不对称氧化胺化成功实 现了氧杂唤丙啶类化合物物的动力学拆分, 回收高对映 选择性的光学氧杂听丙啶原料的同时, 得到中等到良好 对映选择性的 4-恶唑烷酮产物.

2014 年池永贵课题组 ${ }^{[41]}$ 报道了通过 NHC 催化的不 对称 $[3+4]$ 环化反应, 实现了甲亚胺亚胺动力学拆分

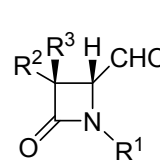

cis $(+/-)$ $\underset{\text { (2) } \mathrm{NaBH}_{4}}{\stackrel{\mathrm{CH}_{2} \mathrm{Cl}_{2}, 25^{\circ} \mathrm{C}}{\longrightarrow}}$ $\mathrm{MeOH}$, r.t.
(1) cat. (5 mol\%)

DBU $(5 \mathrm{~mol} \%)$

$\mathrm{R}^{1}=$ Mes or PMP

$\mathrm{R}^{2}=\mathrm{Ar}$, Alkyl, PMP, 2-thienyl

$\mathrm{R}^{3}=\mathrm{H}, \mathrm{Ph}$, Alkyl

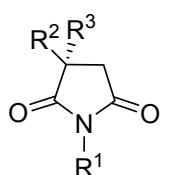

$(+)$

$26 \% \sim 50 \%$ yield $32 \% \sim 47 \%$ yield

$0 \sim 44 \%$ ee $\quad 19 \% \geqslant 99 \%$ ee<smiles>Cc1cc(C)c(-[n+]2cn3c(n2)CO[C@@H]2Cc4ccccc4[C@@H]23)c(C)c1</smiles>

图式 25 手性 NHC 催化的顺式 4-甲酰- $\beta$ 内酰胺动力学拆分 Scheme 25 Chiral NHC-catalyzed KR of cis-4-formyl- $\beta$-lactams
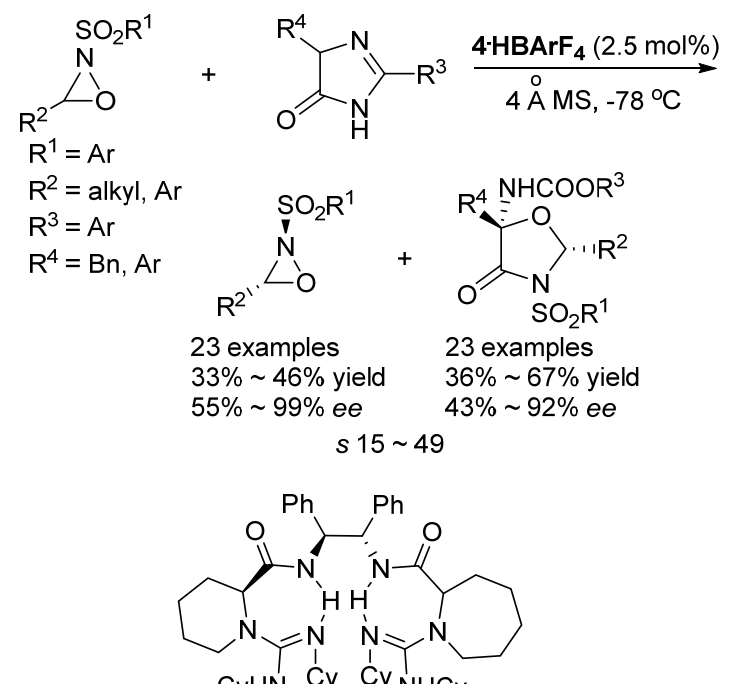

CyHN Cy Cy $\mathrm{NHCy}$

4

图式 26 有机小分子催化的氧杂吅丙啶动力学拆分

Scheme 26 Organocatalyzed KR of oxaziridines

(Scheme 27). 该课题组利用甲亚胺亚胺和共轭烯醛的 不对称环化, 以最高 $93 \%$ 的对映选择性回收了原料, 并 获得了 ee 大于 $93 \%$ 的产物, 拆分系数 $s$ 最高达 339 .

\section{$2 \mathrm{~N}$ 不参与反应的化学动力学拆分}

胺类化合物(一级或二级胺)氮原子的强亲核性和强 配位性通常导致动力学拆分反应效果不佳. 于是. 通过 氮原子不参与不对称催化反应的方法来实现高效动力 学拆分成为化学家们研究的另一种策略. 氮原子不参与 不对称催化反应，不仅能避免胺类化合物自身固有缺 点, 而且还可以在底物结构中引入另一个手性中心, 使 得拆分产物有更多潜在应用前景. 目前, 氮原子不参与 的化学动力学拆分也得到了一些研究和发展.

\section{1 非酶催化的氧化还原反应}

手性氨基酸是生物体的组成部分，同时也是重要的 


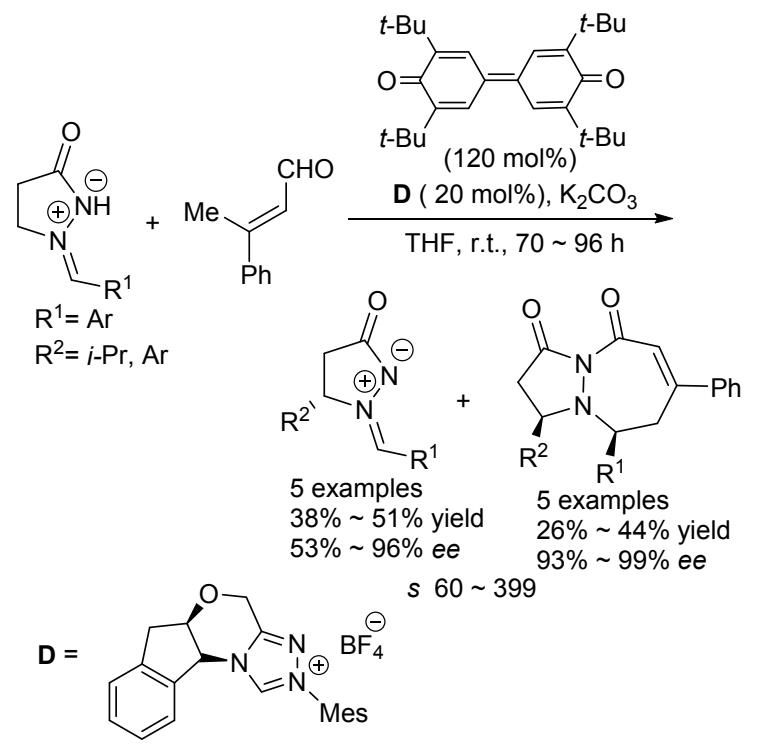

图式 27 手性 NHC 催化的甲亚胺亚胺动力学拆分 Scheme 27 Chiral NHC-catalyzed KR of azomethine imines

有机合成原料及中间体, 具有广泛的药理和生理活性. 因此, 合成光学活性的天然和非天然氨基酸一直吸引着 化学家的兴趣. 2008 年, Onomura 课题组 ${ }^{[42]}$ 报道了氨基 醛类化合物及氨基醇类化合物的氧化动力学拆分 (Scheme 28). 该课题组以 $(R, R)-\mathrm{Ph}-\mathrm{BOX}$ 作为手性配体, 实现了 $\mathrm{Cu}$ 催化的 $\mathrm{N}$-保护的 1.2-氨基醛和 1.2-氨基醇的 不对称电化学氧化反应, 以较低的产率得到高对映选择 性的氨基酸甲酯, 表明了氨基醛类化合物及氨基醇类化 合物的动力学拆分的可行性.

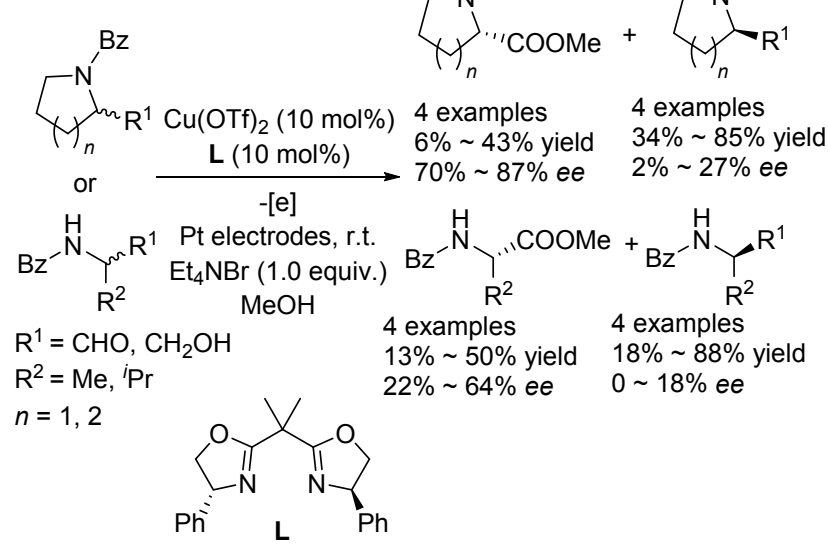

图式 28 铜催化的氨基醇和氨基醛的电化学氧化动力学拆分 Scheme 28 Cu-catalyzed electrochemical OKR of aminoalcohols and aminoaldehydes

之后, Onomura 课题组 ${ }^{[43]}$ 继续研究, 发现当使用 $N$ 碘代琥珀酰亚胺(NIS)作为氧化剂时, 可代替电化学氧 化, 实现铜催化 1.2-氨基醛的选择性 OKR (Scheme 29), 得到光学活性氨基酸甲酯化合物, 同时以氨基醛二甲基
缩醛的形式回收原料. 该催化体系对环状和非环状底物 都有良好的催化活性，能以较高的产率获得对映选择性 最高 $99 \%$ 的氨基酸甲酯化合物，选择系数 $s$ 最高可达 368 ; 但是, 该体系回收的氨基醛二甲基缩醛类原料只 有中等的对映选择性.

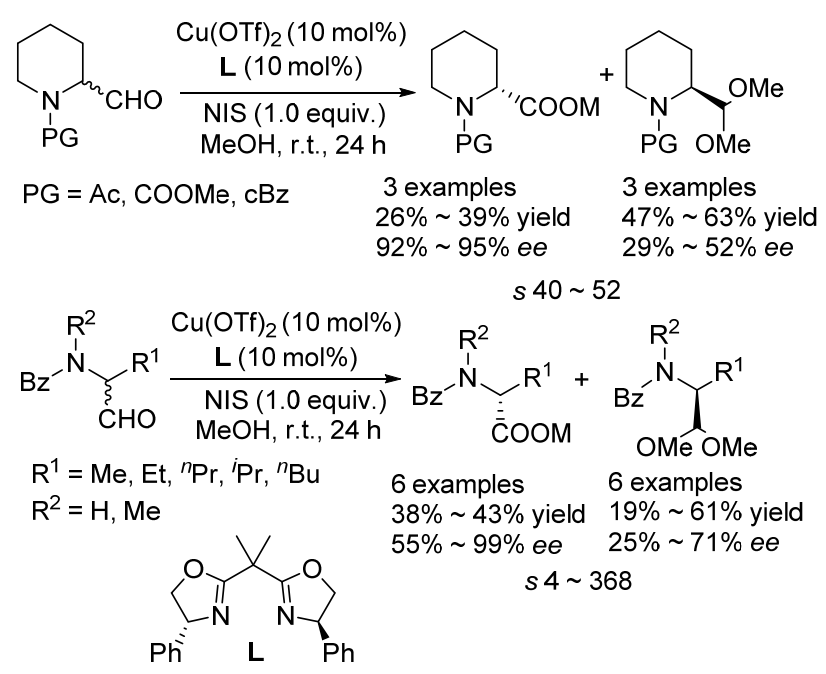

图式 29 铜催化的氨基醛的氧化动力学拆分

Scheme $29 \mathrm{Cu}$-catalyzed OKR of aminoaldehydes

\section{$2.2 \mathrm{~N}$ 不参与反应的的不对称加成动力学拆分}

2009 年, Sibi 课题组 ${ }^{[44]}$ 报道了利用铜催化的选择性 Diels-Alder 环加成反应, 实现吡唑烷酮类化合物的动力 学拆分(Scheme 30). 该课题组使用手性 BOX 配体, 利 用环成二烯和不饱和吡唑烷酮酰亚胺的不对称环加成 反应，得到了高对映选择性的手性吡唑烷酮类化合物， 对映选择性最高可达到 $99 \%$. 该课题组研究表明, 当底 物 $\mathrm{R}^{2}$ 基团为芳基类时，能得到很好的拆分效果.

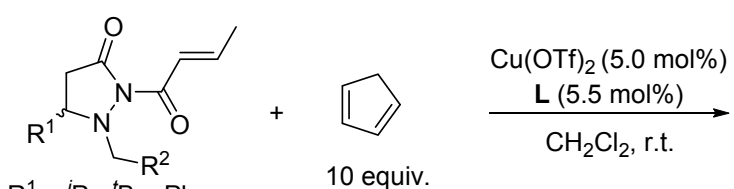

$\mathrm{R}^{1}={ }^{i} \mathrm{Pr},{ }^{t} \mathrm{Bu}, \mathrm{Ph}$

$\mathrm{R}^{2}=\mathrm{Me}, \mathrm{Ph}, 1$-naphthyl<smiles>[R]CN1C([R1])CC(=O)N1C(=O)/C=C\C</smiles>

5 examples $35 \% \sim 40 \%$ yield $86 \% \sim 98 \%$ ee $\quad s 8 \sim 35$

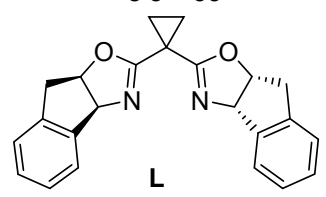

图式 30 铜催化吡唑烷酮的 D-A 动力学拆分 Scheme 30 Cu-catalyzed D-A KR of pyrazolidinones 
2017 年, 侯国华课题组 ${ }^{[45]}$ 报道了利用铜催化的不 对称硼化反应, 实现 1,2-二氢喹啉化合物的动力学拆分 (Scheme 31). 该课题组使用 $\mathrm{CuCl}$ 作为金属盐, JosiPhos-1 作为手性配体, 高效、高选择性地实现了 2-取 代-1,2-二氢喹啉的动力学拆分. 该反应催化体系能够在 $30 \mathrm{~min}$ 内完成底物的动力学拆分, 以优异的选择性 $(d r>99 ： 1,99.7 \% e e)$ 获得了手性硼氢化产物, 同时以 99.4\% ee 的对映选择性回收了未反应的原料. 该方法具 有很好的底物普适性, 2 位芳基或烷基取代的底物均能 得到优秀的拆分效果, 拆分选择系数 $s$ 最高可达 569 .

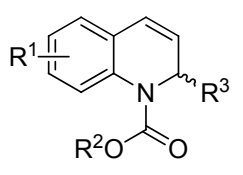

$$
\begin{aligned}
& \underset{\mathrm{CuCl}(5 \mathrm{~mol} \%)}{\mathrm{L}(5 \mathrm{~mol} \%)} \\
& \underset{\mathrm{B}_{2} \operatorname{pin}_{2}(0.6 \text { equiv. })}{\mathrm{MeOK}(0.22 \text { equiv. })} \\
& \mathrm{THF}, \mathrm{MeOH} \\
& 0^{\circ} \mathrm{C}, 30 \mathrm{~min} \sim 2 \mathrm{~h}
\end{aligned}
$$
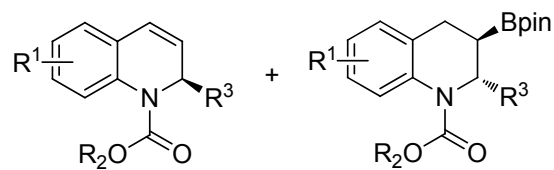

$$
\begin{aligned}
& 18 \text { examples } \\
& 40 \% \sim 47 \% \text { yield } \\
& 98 \% \sim 99.9 \% \text { ee }
\end{aligned}
$$$$
\mathrm{R}^{1}=\mathrm{CH}_{3}, \mathrm{OCH}_{3}
$$$$
\mathrm{R}^{2}=\text { alkyl, } \mathrm{Ph}, \mathrm{Bn}
$$$$
\mathrm{R}^{2}=\text { alkyl, } \mathrm{Ar}
$$

$$
\begin{aligned}
& 18 \text { examples } \\
& 44 \% \sim 48 \% \text { yield } \\
& 90 \% \sim 99 \% \text { ee }
\end{aligned}
$$

图式 31 铜催化 1,2-二氢喹啉化合物不对称嗍化动力学拆分 Scheme 31 Cu-catalyzed borylation KR of 1,2-dihydroquinolines

\section{$2.3 \mathrm{~N}$ 不参与反应的取代反应动力学拆分}

2014 年 Coldham 课题组 ${ }^{[46]}$ 报道了利用 $n-\mathrm{BuLi} /(-)-$ sparteine 或 $n$-BuLi/ $(+)$-sparteine 作为手性碱, 通过不对 称去质子化实现了 $N$-Boc-2-芳基哌啶的动力学拆分, 并 取得了不错的效果(Scheme 32). 该反应对取代芳香环 上有强吸电子基的底物效果很差, 这可能是由于强酸性 底物锂化困难.

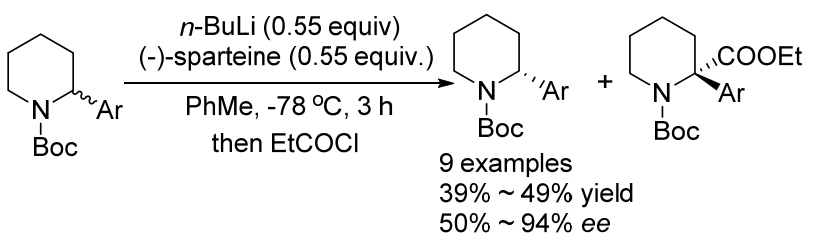

图式 32 手性碱催化的芳基哌啶动力学拆分

Scheme 32 Chiral base-catalyzed KR of arylpiperidines

2014 年侯雪龙课题组 ${ }^{[47]}$ 利用钯催化不对称烯丙基 烷基化反应，实现了 2-取代 2,3-二氢-4-吡啶酮类化合物 的动力学拆分 (Scheme 33). 该反应以 (S)-P-PHOS 作为 手性配体, 以烯丙基碳酸甲酯作为亲电试剂, 在低温下
反应，得到较高对映选择性的反式烯丙基化产物的同 时, 能够以中等到良好的对映选择性回收 2-取代 2,3-二 氢-4-吡啶酮类原料，拆分系数 $s$ 在 11 到 43 之间, 2 位取 代基对产物的对映选择性影响较小, 但是对对回收原料 的对映选择性影响很大.

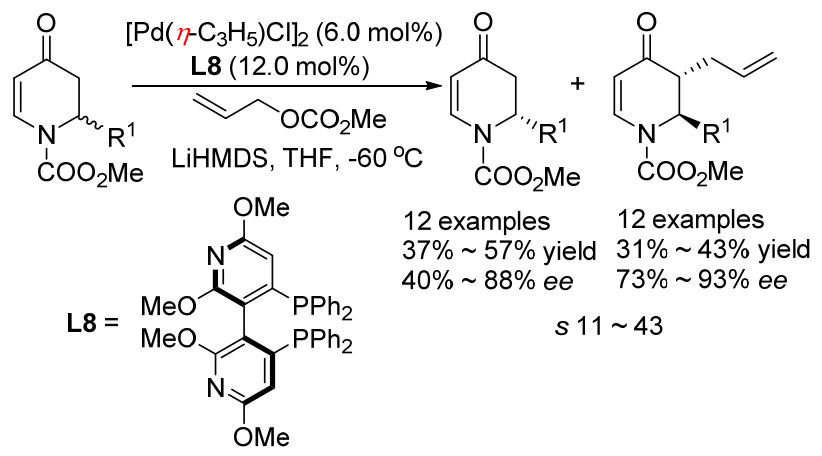

图式 33 钯催化的吡啶酮烯丙基烷基化动力学拆分 Scheme 33 Pd-catalyzed allylic alkylation KR of pyridones

\section{$2.4 \mathrm{~N}$ 不参与反应的 $\mathrm{C}-\mathrm{H}$ 活化动力学拆分}

目前, 钯催化的不对称 $\mathrm{C}-\mathrm{H}$ 活化已经得到了许多 研究和发展, 将不对称 $\mathrm{C}-\mathrm{H}$ 交叉偶联应用于外消旋苄 胺动力学拆分反应, 显得十分有吸引力, 因为这种方法 将得到手性苄胺和手性邻芳基茮胺两种具有广泛应用 价值的骨架. 2016 年, Yu 课题组 ${ }^{[48]}$ 报道了利用不对称 $\mathrm{C}$ - $\mathrm{H}$ 官能化实现茮胺类化合物的动力学拆分 (Scheme 34 ). 该反应利用氨基酸衍生物 Boc- $L-\mathrm{Bn}-\mathrm{NHOMe}$ 为手 性配体，与芳基硼酸酯在 $\mathrm{N}_{2}$ 条件下发生偶联反应，得到 了高对映选择性邻芳基茮胺产物的同时回收了高对映 选择性的苄胺原料. 该反应具有良好的拆分效果，拆分 系数 $s$ 最高可达 135, 并且对各种取代茮胺和取代芳基 嗍酸酯都有良好的官能团耐受性.

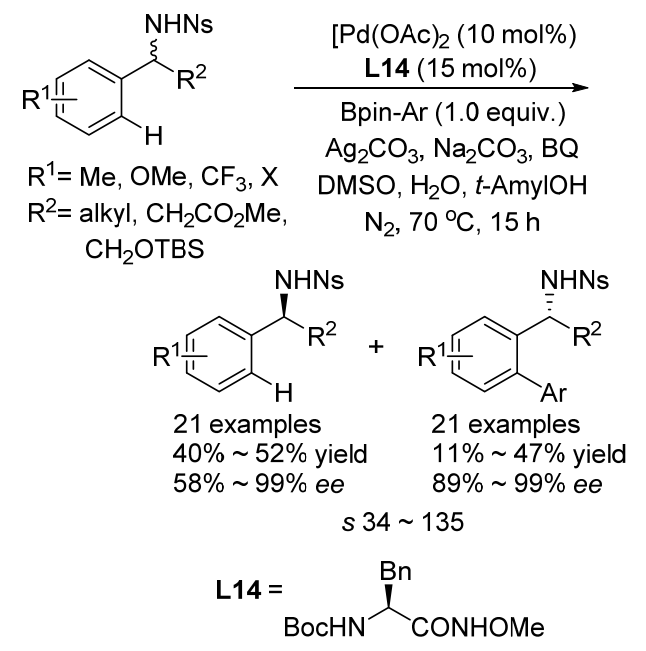

图式 34 钯催化的芐胺 $\mathrm{C}-\mathrm{H}$ 活化动力学拆分 Scheme 34 Pd-catalyzed $\mathrm{C}-\mathrm{H}$ activation KR of benzylamines 
2019 年, 徐森苗课题组 ${ }^{[49]}$ 利用 $\operatorname{Ir}$ 催化的不对称 $\mathrm{C}-\mathrm{H}$ 硼化, 实现了外消旋二芳甲基胺的 $\mathrm{C}-\mathrm{H}$ 活化动 力学拆分 (Scheme 35). 当外消旋二芳甲基胺的两个芳 基取代基不同, 在进行 $\mathrm{C}-\mathrm{H}$ 活化时, 就会出现区域选 择性. 如果催化剂能够区分两个光学异构体, 即可实现 二芳甲基胺类化合物的动力学拆分. 于是该课题组利用 手性双齿硣酸配体，成功实现了芳基取代基不同的二芳 甲基胺类的动力学拆分, 得到对映选择性最高 $93 \%$ 的喼 化产物. 然而只能回收对映选择性中等到良好的二芳甲 基胺原料，根据苯环取代基的电子性质和位置，这些反 应给出的选择系数 $s$ 值在 $9 \sim 68$ 之间.<smiles>[R]c1cc([R])cc(C(c2[R]cccc2)N(C)C)c1</smiles>

$$
\begin{aligned}
& \left.\underset{[\operatorname{lrCl}(\mathrm{COD})]_{2}(2.5 \mathrm{~mol} \%)}{\mathrm{L}(5 \mathrm{~mol} \%)}\right) \\
& \underset{\mathrm{B}}{\mathrm{B}_{2} \operatorname{pin}_{2}(0.6 \text { equiv. })} \\
& \mathrm{THF}, 70^{\circ} \mathrm{C}, 24 \sim 48 \mathrm{~h}
\end{aligned}
$$<smiles>[R]c1cc([R])cc(C(NCc2ccccc2)c2ccccc2)c1</smiles>

11 examples $27 \% \sim 54 \%$ conv. $72 \% \sim 94 \%$ ee

$\mathrm{R}^{1}=\mathrm{Me}, \mathrm{OMe}, \mathrm{CF}_{3}, \mathrm{X}$ $\mathrm{R}^{2}=\mathrm{Me}, \mathrm{OMe} \mathrm{CF}_{3}, \mathrm{X}$ $\mathrm{R}^{3}=\mathrm{H}, \mathrm{Me}, \mathrm{Ph}, \mathrm{X}$<smiles>[R]c1cc([R])cc(C(C)c2ccccc2)c1</smiles>

11 examples $27 \% \sim 54 \%$ conv. $28 \% \sim 88 \%$ ee

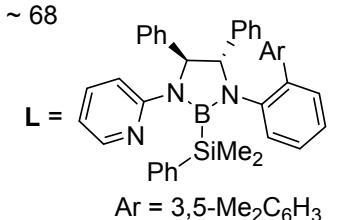

图式 $35 \mathrm{Ir}$ 催化的二芳甲基胺 $\mathrm{C}-\mathrm{H}$ 硼化动力学拆分 Scheme 35 Ir-catalyzed $\mathrm{C}-\mathrm{H}$ borylation KR of diarylmethylamines

\section{3 结论与展望}

虽然近年来胺的动力学拆分的研究有了新的发展, 但相较于醇的动力学拆分, 就以下几方面仍然有待进一 步发展. (1)拓展更多的氮参与反应的胺的不对称催化动 力学拆分方法, 从而实现各类胺的手性拆分. (2)开发氮 不参与反应的不对称反应的动力学拆分方法, 不但能实 现更多类型胺的动力学拆分, 同时也能为高效构建多手 性中心的含氮化合物提供新方法. (3)研究开发胺的动态 动力学拆分, 突破动力学拆分的最高只有 $50 \%$ 收率的限 制.

\section{References}

[1] Yoshimura, H.; Oguri, K.; Tsukamoto, H. Tetrahedron Lett. 1968, 9 , 483.

[2] Lautens, M.; Rovis, T. J. Org. Chem. 1997, 62, 5246.

[3] Jeffery, J. E.; Kerrigan, F.; Miller, T. K.; Smith, G. J.; Tometzki, G. B. J. Chem. Soc., Perkin Trans. 1996, 2583.

[4] Stoner, E. J.; Cooper, A. J.; Diclcman, D. A.; Kolaczkowslti, L.; Lallaman, J. E.; Liu, J. H.; Oliver-Shaffer, P A.; Patel, K. M.; Pat- erson, J. B.; Plata, D. J.; Riley, D. A.; Sham, H. L.; Stengel, P J.; Tien, J. H. Org. Proc. Res. Dev. 2000, 4, 264.

[5] France, S.; Guerin, D. J.; Miller, S. J.; Lectka, T. Chem. Rev. 2003, 103, 2985

[6] (a) Vedejs, E.; Jure, M. Angew. Chem., Int. Ed. 2005, 44, 3974. (b) Kagan, H. B.; Fiaud, J.-C. Top. Stereochem. 1988, 18, 249.

[7] Keith, J. M.; Larrow, J. F.; Jacobsen, E. N. Adv. Synth. Catal. 2001, 343,5 .

[8] (a) Arai, S.; Bellemin-Laponnaz, S.; Fu, G. C. Angew. Chem., Int Ed. 2001, 40, 234.

(b) De, C. K.; Klauber, E. G.; Seidel, D. J. Am. Chem. Soc. 2009, 131, 17060 .

(c) Klauber, E. G.; De, C. K.; Shah, T. K.; Seidel, D. J. Am. Chem. Soc. 2010, 132, 13624.

(d) Mittal, N.; Lippert, K. M.; De, C. K.; Klauber, E. G.; Emge, T. J.; Schreiner, P. R.; Seidel, D. J. Am. Chem. Soc. 2015, 137, 5748.

(e) Birman, V. B.; Jiang, H.; Li, X.; Guo, L.; Uffman, E. W. J. Am. Chem. Soc. 2006, 128, 6536.

(f) Yang, X.; Bumbu, V. D.; Liu, P.; Li, X.; Jiang, H.; Uffman, E. W.; Guo, L.; Zhang, W.; Jiang, X.; Houk, K. N.; Birman, V. B. J. Am. Chem. Soc. 2012, 134, 17605.

(g) Arseniyadis, S.; Valleix, A.; Wagner, A.; Mioskowski, C. Angew. Chem., Int. Ed. 2004, 43, 3314.

(h) Arseniyadis, S.; Subhash, P. V.; Valleix, A.; Mathew, S. P.; Blackmond, D. G.; Wagner, A.; Mioskowski, C. J. Am. Chem. Soc. 2005, 127, 6138 .

[9] (a) Birman, V. B.; Jiang, H.; Li, X.; Guo, L.; Uffman, E. W. J. Am. Chem. Soc. 2006, 128, 6536.

(b) Yang, X.; Bumbu, V. D.; Liu, P.; Li, X.; Jiang, H.; Uffman, E. W.; Guo, L.; Zhang, W.; Jiang, X.; Houk, K. N.; Birman, V. B. J. Am. Chem. Soc. 2012, 134, 17605.

(c) Fowler, B. S.; Mikochik, P. J.; Miller, S. J. J. Am. Chem. Soc. 2010, 132, 2870 .

(d) Bumbu, V. D.; Yang, X.; Birman, V. B. J. Am. Chem. Soc. 2011, 133, 13902 .

(e) Bumbu, V. D.; Yang, X.; Birman, V. B. Org. Lett., 2013, 15, 279.

[10] For representative reports on OKR, see: (a) Ferreira, E. M.; Stoltz, B. M. J. Am. Chem. Soc. 2001, 123, 7725.

(b) Muller, J. A.; Sigman, M. S. J. Am. Chem. Soc. 2003, 125, 7005. (c) Nishibayashi, Y.; Yamauchi, A.; Onodera, G.; Uemura, S. J. Org. Chem. 2003, 68, 5875.

(d) Radosevich, A. T.; Musich, C.; Toste, F. D. J. Am. Chem. Soc. 2005, 127, 1090 .

(e) Pawar, V. D.; Bettigeri, S.; Weng, S.-S.; Kao, J.-Q.; Chen, C.-T. J. Am. Chem. Soc. 2006, 128, 6308 .

(f) Chen, T.; Jiang, J.-J.; Xu, Q.; Shi, M. Org. Lett. 2007, 9, 865

(g) Arita, S.; Koike, T.; Kayaki, Y.; Ikariya, T. Angew. Chem., Int. Ed. 2008, 49, 2447.

(h) Tomizawa, M.; Shibuya, M.; Iwabuchi, Y. Org. Lett. 2009, 11 1829 .

(i) Kunisu, T.; Oguma, T.; Katsuki, T. J. Am. Chem. Soc. 2011, 133, 12937.

[11] (a) Miyano, S.; Lu, L. D.-L.; Viti, S. M.; Sharpless, K. B. J. Org Chem. 1983, 48, 3608 .

(b) Miyano, S.; Lu, L. D.-L.; Viti, S. M.; Sharpless, K. B. J. Org. Chem. 1985, 50, 4350.

(c) Hayashi, M.; Okamura, M.; Toba, T.; Oguni, N.; Sharpless, K. B. Chem. Lett. 1990, 547.

[12] Bhadra, S.; Yamamoto, H. Angew. Chem., Int. Ed. 2016, 55, 13043.

[13] Saito, K.; Shibata, Y.; Yamanaka, M.; Akiyama, T. J. Am. Chem. Soc. 2013, 135, 11740 .

[14] (a) Tsutsui, H.; Narasaka, K. Chem. Lett. 1999, $28,45$.

(b) Tsutsui, H.; Kitamura, M.; Narasaka, K. Bull. Chem. Soc. Jpn. 2002, 75, 1451.

[15] Saito, K.; Akiyama, T. Angew. Chem., Int. Ed. 2016, 55, 3148.

[16] Lu, R.; Cao, L.; Guan, H.; Liu, L. J. Am. Chem. Soc. 2019, 141, 6318.

[17] (a) Tanner, D. Angew. Chem., Int. Ed. Engl. 1994, 33, 599. 
(b) Fruit, C.; Müller, P. Chem. Rev. 2003, 103, 2905.

[18] Cockrell, J.; Wilhelmsen, C.; Rubin, H.; Martin, A.; Morgan, J. B. Angew. Chem., Int. Ed. 2012, 51, 9842 .

[19] Ohmatsu, K.; Hamajima, Y.; Ooi, T. J. Am. Chem. Soc. 2012, 134, 8794.

[20] Ohmatsu, K.; Ando, Y.; Ooi, T. J. Am. Chem. Soc. 2013, 135, 18706.

[21] Monaco, M.R.; Poladura, B.; De Los Bernardos, M. D.; Leutzsch, M.; Goddard, R.; List, B. Angew. Chem., Int. Ed. 2014, 53, 7063.

[22] Zhu, Y. M.; Yang, P. J.; Wang, S.; Liu, Z.; Yang, G.; Chai, Z. J. Am. Chem. Soc. 2015, 137, 10088.

[23] Yang, P. J., Zhang, H.; Wang, S.; Yang, G.; Chai, Z. Angew. Chem., Int. Ed. 2017, 56, 650

[24] Zhang, F.; Zhang, Y.; Tan, Q.; Lin, L.; Liu, X.; Feng, X. Org. Lett. 2019, 21, 5928.

[25] Chen, X.; Vedejs, W. J. Am. Chem. Soc. 1997, 119, 2584.

[26] Wu, B.; Parquette, J. R.; RajanBabu, T. V. Science 2009, 326, 1662.

[27] Wu, B.; Gallucci, J. C.; Parquette, J. R.; RajanBabu, T. V. Chem. Sci. 2014, 5, 1102.

[28] Xu, Y.; Kaneko, K.; Kanai, M.; Shibasaki, M.; Matsunaga, S. J. Am. Chem. Soc. 2014, 136, 9190.

[29] Hu, H.; Liu, Y.; Lin, L.; Zhang, Y.; Liu, X.; Feng, X. Angew. Chem., Int. Ed. 2016, 55, 10098.

[30] An, D.; Guan, X.; Guan, R.; Jin, L.; Zhang, G.; Zhang, S. Chem. Commun. 2016, 52, 11211 .

[31] Zheng, B. H.; Hou, X.-L. Org. Lett. 2009, 11, 1789 .

[32] Wang, Y., Xu, Y.-N.; Fang, G.-S.; Kang, H.-J.; Gu, Y.; Tian, S.-K. Org. Biomol. Chem. 2015, 13, 5367.

[33] Li, M.-B.; Li, H.; Wang, J.; Liu, C.-R.; Tian, S.-K. Chem. Commun. 2013, 49, 8190

[34] Liu, C.-R.; Li, M.-B.; Yang, C.-F.; Tian, S.-K. Chem.-Eur. J. 2009,
$15,793$.

[35] Wu, X.-S.; Tian, S.-K. Chem. Commun. 2012, 48, 898.

[36] Yang, W.; Long, Y.; Zhang, S.; Zeng, Y.; Cai, Q. Org. Lett. 2013, $15,3598$.

[37] Narine, A. A.; Toulgoat, F.; Bisschops, T.; Enders, D. Angew. Chem., Int. Ed. 2008, 47, 5661 .

[38] Reznichenko, A. L.; Hampel, F.; Hultzsch, K. C. Chem.-Eur. J. 2009, 15, 12819 .

[39] Li, G.-Q.; Li, Y.; Dai, L.-X.; You, S.-L. Adv. Synth. Catal. 2008, $350,1258$.

[40] Dong, S.; Liu, X.; Zhu, Y.; He, P.; Lin, L.; Feng, X. J. Am. Chem. Soc. 2013, 135, 10026.

[41] Wang, M.; Huang, Z.; Xu, J.; Chi, Y. R. J. Am. Chem. Soc. 2014 $136,1214$.

[42] Minato, M.; Arimoto, H.; Nagasue, Y.; Demizu, Y.; Onomura, O. Tetrahedron 2008, 64, 6675 .

[43] Minato, D.; Nagasue, Y.; Demizu, Y.; Onomura, O. Angew. Chem., Int. Ed. 2008, 47, 9458.

[44] Sibi, M. P.; Kawashima, K.; Stanley, L. M. Org. Lett. 2009, 11, 3894.

[45] Kong, D.; Han, S.; Wang, R.; Li, M.; Zi, G.; Hou, G. Chem. Sci. 2017, 8,4558

[46] Cochrane, E. J.; Leonori, D.; Hassallb, L. A.; Coldham, I. Chem. Commun. 2014, 50, 9910.

[47] Lei, B.-L.; Zhang, Q.-S.; Yu, W.-H.; Ding, Q.-P.; Ding, C.-H.; Hou, X.-L. Org. Lett. 2014, 16, 1944.

[48] Xiao, K.-J.; Chu, L.; Chen, G.; Yu, G.-Q. J. Am. Chem. Soc. 2016, $138,7796$.

[49] Zou, X.; Zhao, H.; Li, Y.; Gao, Q.; Ke, Z.; Xu, S. J. Am. Chem. Soc. 2019, 141,5334 